\title{
Seismic Potential Improvement of Road Embankment
}

\author{
Ken-ichi Tokida \\ Osaka University \\ Japan
}

\section{Introduction}

Roads or highways are very important and fundamental infrastructures for the activities of life and production, and their safety are required to be secured against the various disasters such as rainfalls and earthquakes etc. The road networks are composed of many types of attached structures such as bridges, embankments, slopes, tunnels etc. During earthquakes, the abovementioned structures have been damaged in the past earthquakes and will be possible to be damaged in the near future.

For reducing the damage potential of the road networks, the seismic design and/or countermeasures for bridges have been conducted prior to other structures in the last about 40 years in Japan because bridges are considered to be difficult to retrieve when they will be damaged by earthquakes. On the other hand, road embankments have not been reinforced at all against seismic disasters because it is believed that embankments can be retrieved easily.

However, severe damages of road embankments have been occurred and it has been clarified that the performance of road networks can be lost severely for a long time, for example, 2 weeks by the damages of road embankments because it needs a long time to retrieve numbers of damaged embankments and the ones located at the mountainous area.

As mentioned above, road embankments are also necessary to be reinforced against seismic ground motion, in other words, the seismic potential of road embankments should be improved against seismic ground motion during future earthquakes.

However the performance-based design will be very reasonable and effective for improving the seismic design of road embankments in the future, the design concepts have not been clarified yet and necessary to be established as soon as possible, similarly with bridges.

In this chapter, based on the typical damages of road embankments induced by recent earthquakes in Japan, the macroscopic assessment method for seismic potential of road embankments and the new concepts for the performance-based design of road embankments from the engineering view points are proposed and their applications are discussed through large-scaled field tests, centrifuge tests and analytical simulations. The following concerns summarizes the results of the recent research and development initiated by Osaka University in Japan from 2004 to the present through Tokida et al. (2007), Tokida et al. (2008), Tatta et al. (2009), Tokida et al.(2009) and Tokida et al. (2010). 


\section{Damage of road embankment in past earthquakes in Japan}

During the recent decade in Japan, severe damages of many road embankments occurred during the earthquakes such as the 2004 Mid-Niigata Prefecture Earthquake, the 2007 Noto Peninsula Earthquake, the 2009 Suruga Bay Earthquake and the 2011 Off the Pacific Coast of Tohoku Earthquake. The typical characteristics of damages of road embankments and the several important lessons obtained can be indicated as follows from the engineering view points.

\subsection{The 2004 Mid-Niigata prefecture earthquake}

The 2004 Mid-Niigata Prefecture Earthquake is an inland earthquake and occurred at the mountainous area in October 23, 2004. The middle-class magnitude of this earthquake is 6.8 and the shallow depth of epicenter is $13 \mathrm{~km}$.

Fig. 1 shows the time history just after the main shock occurrence for opening Kanetsu Highway and Hokuriku Highway which were stopped mainly by the damages relating to not the bridges but the embankments to the emergency vehicles such as ambulances etc. and the public cars. It can be seen it took about 13 days to open the highways for the personal vehicles under the speed regulation. As mentioned above, we can realize the importance of seismic design and reinforcement for road embankments in the future.

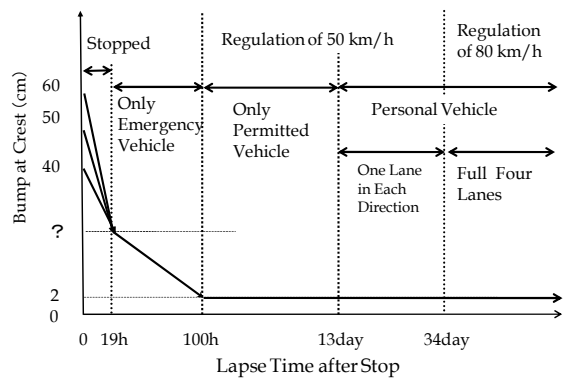

Fig. 1. Recovery of traffic performance after stopping caused by earthquake

Item 2 on the status of drainage system can be selected because the damage risk relates to the level of moisture in the embankment. For example, the assessment rank and each relating score are assumed as follows.

The typical examples of severe or large-scaled damages and slight or small-scaled damages of road embankments can be shown as Photo. 1 and Photo. 2, respectively. The former indicates three examples, i.e. (a) very severely damaged site reported by Higashi Nippon Highway Co. Ltd. where all 4 lanes were slid perfectly, (b) severely damaged site reported by Hokuriku Regional Bureau of Ministry of Land and Transportation where all 2 lanes were slid perfectly and (c) a little severely damaged site also reported by Hokuriku Regional Bureau where almost 2 lanes were slid partially and each traffic performance was lost perfectly. While, the latter indicates two examples, i.e. (a) partially slid site also reported by Hokuriku Regional Bureau where the sliding occurred only at the shoulder of the embankment and was retrieved easily with large-scaled sand bags as shown in Photo. 2, and (b) cracked site reported by Higashi Nippon Highway Co. Ltd. where only the shoulder was cracked a little and dump trucks can run without urgent retrieval, then their loss of traffic 
performance were small and the road could be used just after the earthquake by small-scale and short-time restoration or not.

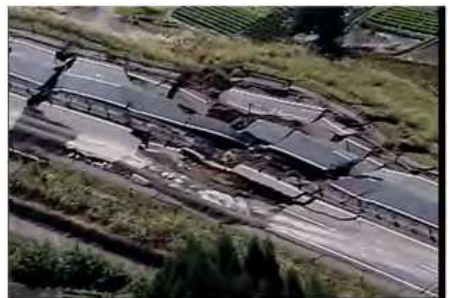

(a) 4 lanes slid perfectly

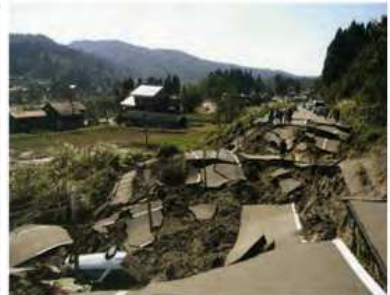

(b) 2 lanes slid perfectly

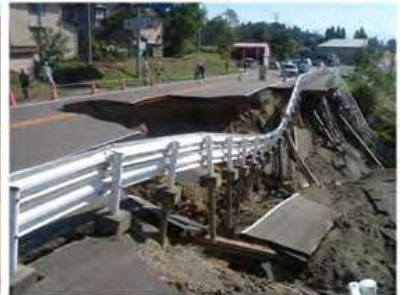

(c) Almost 2 lanes slid

Photo 1. Large-scaled damage of road embankment without traffic performance

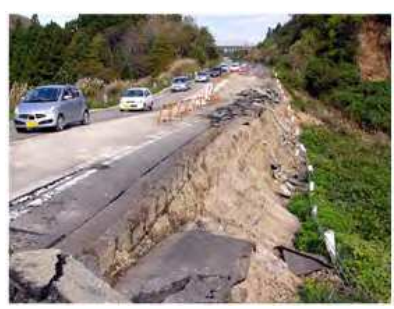

(a) Partial sliding and urgent retrieval with sand bags

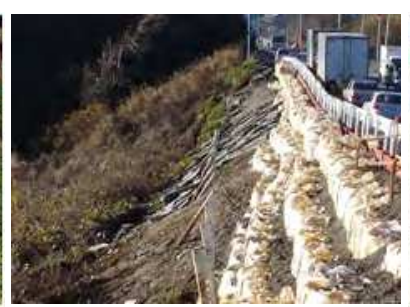

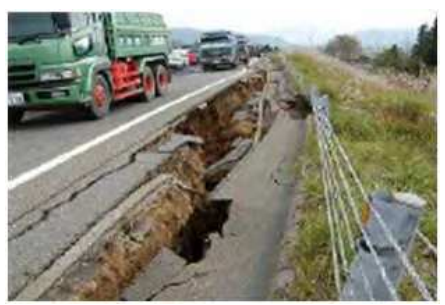

(b) Slight crack at shoulder

Photo 2. Small-scaled damage of road embankment with a certain traffic performance

The above two types of damage levels of road embankments give us the important lessons to consider the fundamental concepts for the performance-based design of road embankments in the future which are shown in Chapter 3.

\subsection{The 2007 Noto peninsula earthquake}

The 2007 Noto Peninsula Earthquake is one type of inland earthquakes and occurred near the coast of Noto Peninsula in March 25, 2007. The middle-class magnitude of this earthquake is 6.9 and the shallow depth of epicenter is $11 \mathrm{~km}$.

Photo.3 reported by Ishikawa Prefecture shows four examples of the slid road embankments which locate at Noto Toll Road at the mountainous area of Noto Peninsula. These photos indicate (a) severe damaged site where 2 lanes were slid perfectly, (b) severe damaged site where almost 2 lanes were slid, (c) severe damaged site where slight 2 lanes were slid and (d) severe damaged site where one side of 2 lanes slid and each traffic performance was lost perfectly.

The severe sliding damages such as Photo. 3 which resulted in the perfect stopping of traffic performance occurred at 13 sites located along the road of about $48.2 \mathrm{~km}$. The site shown in Photo. 3(c) is selected to apply the analytical method named Newmark Method to simulate the sliding plane and its displacement in Chapter 5.

In Photo. 4 reported by Ishikawa Prefecture, Photo. 4(a) shows the severe damaged on ramp close to the toll gate. Most damaged embankments were retrieved urgently and permanently with use of the geotextile which can be shown in Photos. 4(b) and 4(c), respectively. Noto Toll Road was opened to the public urgently in about one month later 
after the earthquake and the permanent retrieval of all damaged embankments was completed in about five months later after the urgent retrieval.

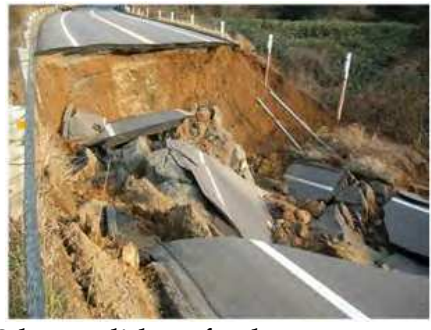

(a) 2 lanes slid perfectly

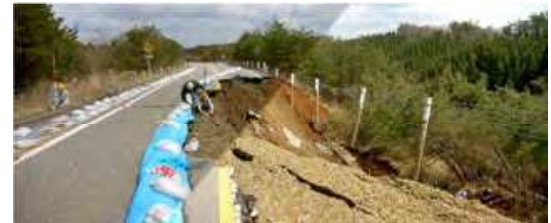

(c) A little more 1 lane slid

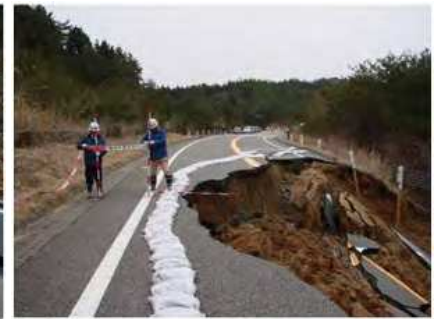

(b) Almost 2 lanes slid perfectly

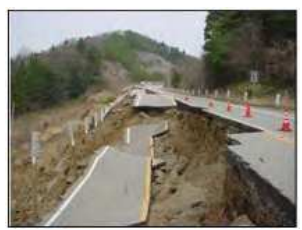

(d) 1 lane slid/1 lane remain

Photo 3. Large-scaled damage of road embankment without traffic performance

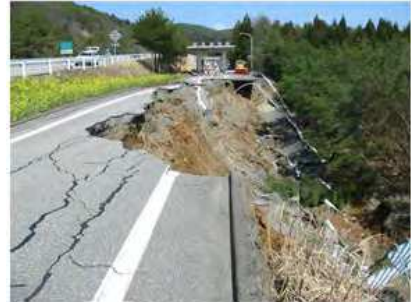

(a) Sliding of entrance lane

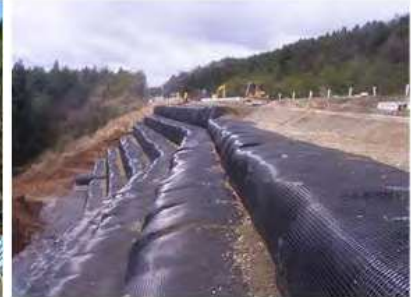

(b) Urgent retrieval

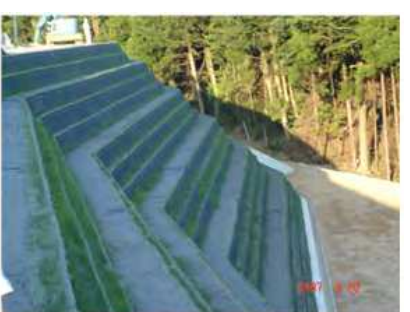

(c) Permanent retrieval

Photo 4. Damage and seismic retrieval with geotextile

It can be indicated that the seismic design with the seismic coefficient of 0.2 was applied to reinforce the retrieved embankments strongly more than that before the earthquake for the future earthquakes. Such seismic retrieval for the road embankments at Noto Toll Road may be the first case in Japan and can be referred for other embankments in the future.

\subsection{The 2009 Suruga bay earthquake}

The 2009 Suruga Bay Earthquake is a plate-slid earthquake and occurred at Suruga bay neighboring to Pacific Ocean in August 11, 2009. The middle-class magnitude of this earthquake is 6.6 and the depth of epicenter is $20 \mathrm{~km}$.

In this earthquake, only one embankment slid at Tohmei Highway which is the most important trunk road between Tokyo and Nagoya as shown in Photo. 5 reported by Naka Nippon Highway Co. Ltd. However the sliding occurred partially at the shoulder and slope as shown in Photo. 5(a) and (b), the traffic performance was lost for about 5 days and the 
economical influences and so on were very large for Japan. However the urgent and extended retrieval was executed, it took 5 days to recover the limited traffic performance for the personal vehicles as shown in Photo. 5(c). The permanent retrieval ended on June 10, 2010, i.e. in about ten months and the traffic performance was recovered perfectly.

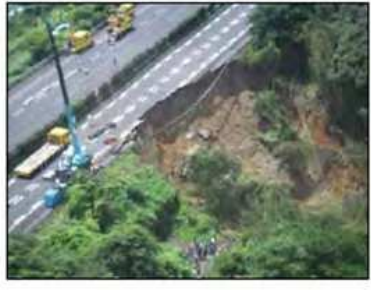

(a) Overview of sliding

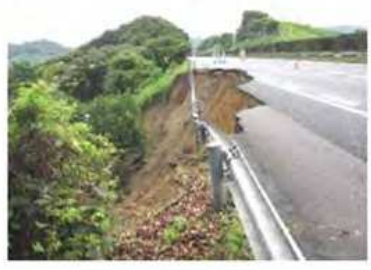

(b) Shoulder and slope slid

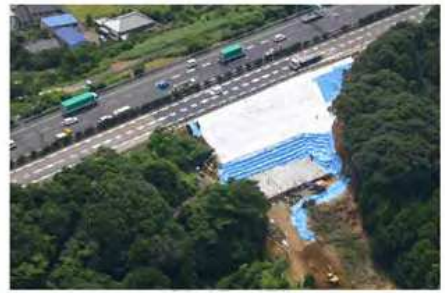

(c) Urgent retrieval

Photo 5. Partially damaged site without traffic performance and urgent retrieval

We can get the important lesson from this experience that the only one damaged site warns the more severe damages of embankments by the very large earthquakes named Tokai Earthquake and/or Tokai \& Nankai Earthquake whose occurrence has been indicated around this site in the near future in Japan.

\subsection{The 2011 off the pacific coast of Tohoku earthquake}

The 2011 Off the Pacific Coast of Tohoku Earthquake is a typical plate-slid earthquake and occurred about $130 \mathrm{~km}$ off the main island of Japan in March 11, 2011. The very large-class magnitude of the earthquake is 9.0 and the depth of epicenter is $24 \mathrm{~km}$. The very wide area where post earthquakes occurred and/or are occurring at present, i.e. the scale of moved plate by the main-shock and after-shocks is assumed to be $200 \mathrm{~km}$ multiplied by $500 \mathrm{~km}$. The outline on the charactoristics of the earthquake and the observed ground motion can be referred the prompt reports by the Japan Meteorological Agency (JMA) and the National Research Institute for Earth Science and Disaster Prevention (NIED), respectively.

However the damages by tsunami occurred widely and severely, other damages of civil engineering structures such as road bridges, road embankments, river dykes and so on were not so remarkable because the epicenter of the main-shock is rather far and the damages occurred along the coasts may be washed away by tsunami attacks. The most severely damaged embankment of all ones at Tohoku Highway and Joban Highway which are the main trunk routes to connect Tokyo with Tohoku Region, where the earthquake occurred can be introduced as shown in Photo. 6 reported by Kanto Branch Office of Higashi Nippon Highway Co. Ltd. As shown in Photo. 6(a), the one side of 2 lanes in one direction slid. However the thickness of the soft ground beneath the embankment body is about $3.6 \mathrm{~m}$, the type of the failure is a toe sliding failure and a little small failure. The work flow of the urgent retrieval for this embankment can be shown as Photo. 6(b), 6(c) and 6(d), respectively. As shown in Photo. 7 under urgent retrieval work, the height and the damaged length of the embankment are about $8 \mathrm{~m}$ and $150 \mathrm{~m}$, respectively. The traffic performance for the personal vehicles was recovered urgently on March 21, 2011. Then it takes about 10 days to complete the urgent retrieval and open the highway to the public. 


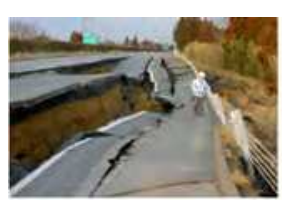

(a) Crushed

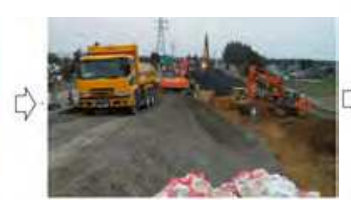

(b) Sliding occurrence

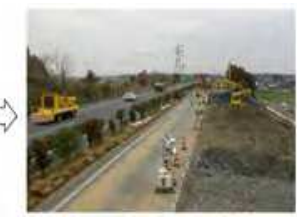

(b) Urgent retrieval with gravel and soil

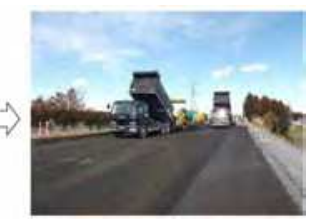

(c) Pavement

Photo 6. One side of two lanes damaged and urgent retrieval

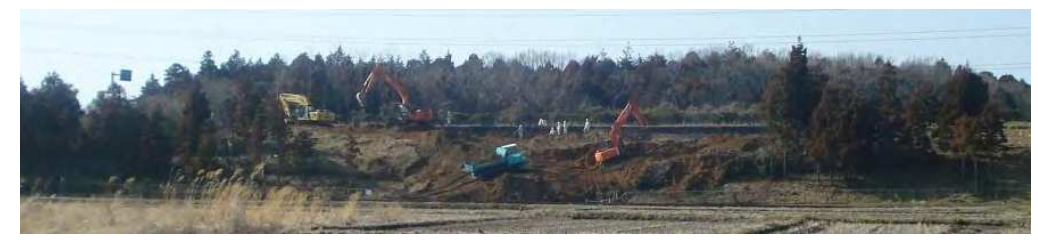

Photo 7. Under urgent retrieving

Some lessons concerning to road embankments against tsunami attacks can be obtained as follows. Photo. 8 is a newly constructed river dyke along the channel which locates in Miyagi Prefecture facing the Pacific Ocean where the earthquake occurred. As shown in the Photo. 8, the river dyke which height and width at the crest are about $4 \mathrm{~m}$ and $6 \mathrm{~m}$, respectively is paved and can be used as a road. Then the lessons obtained from the damages of this dyke can be applied for the future design against tsunami disasters. Photo. 8(a) shows the condition of the front side of dyke slope against tsunami attacks which came from the left side of the Photo. 8(a). It can be seen that almost all of the front sides were not damaged, i.e. the front side may be strong against tsunami attacks which height is assumed to be about $10 \mathrm{~m}$ around this site and then the overflown water depth at the dyke crest can be estimated to be about $4 \mathrm{~m}$. Photo. $8(\mathrm{~b})$ shows the condition at the dyke crest where the asphalt pavements are stripped partially, but the road function was not lost so much. Then it can be indicated that the asphalt pavement at the crest is very effective against the overflowed water by tsunami. Photo. 8(c) shows the conditions of the back side of dyke slope washed away by tsunami. It can be known that the back side slope is eroded near the surface and the toe ground is eroded severely and trenched deeply. However the back side slope is fallen down partially, the minimum stability of the dyke can be maintained to keep the performance of the dyke and/or road. However the above lessons may be limited to this dyke, they become very important hints for the design against tsunami attacks.

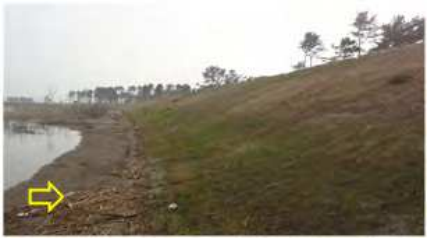

(a) Front slope non-damaged

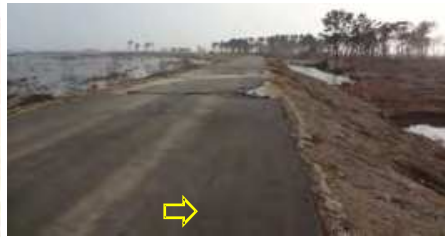

(b) Crest stripped partially

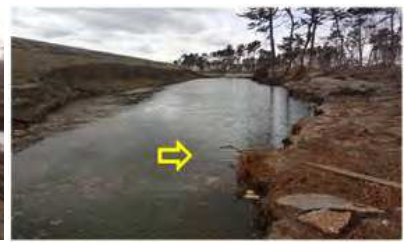

(c) Back slope and toe eroded

Photo 8. Dyke overflown by tsunami 


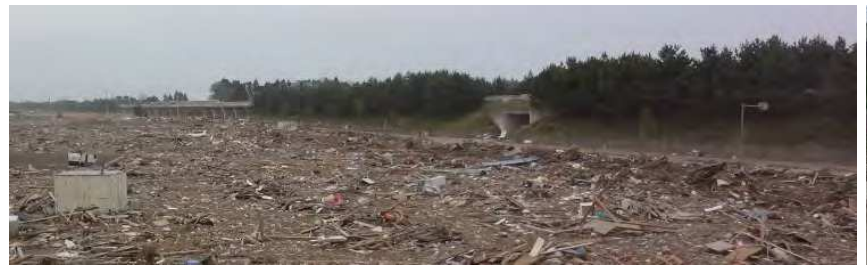

(a) Opposite side from sea

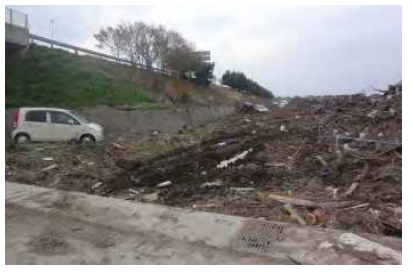

(b) Sea side

Photo 9. Comparison of damages at both sides of highway embankment

Photo. 9 shows another example from which we can get some lessons on the performance of the road embankments against tsunami attacks. Photos. 9(a) and 9(b) show the landscapes after tsunami attacks at the opposite side and the front side of the road embankment against tsunami attacks, respectively. However the road embankment was expected to perform the barrier function against tsunami attacks, the performance may be small as shown in Photo. 9(a) because the box culvert and the elevated bridge permit tsunami flow to go through.

From this example, it can be known that the road embankment may be effective as a barrier against tsunami when the open space such as box culvert etc. can be constructed carefully considering tsunami attacks.

\section{Macroscopic assessment for seismic potential of road embankments}

It is necessary to select the objective road embankments with high seismic potential for the further detail investigations and the economical countermeasures against future earthquakes. Based on the damages in the past earthquakes as shown in Chapter 2, the assessment items and ranks for elemental functions traversing damage of embankments caused by the sliding failure can be obtained and a macroscopic assessment method to estimate the seismic potential of the road embankments can be proposed as follows.

\subsection{Factors related to damage potential}

Macroscopic assessment methods of seismic and disaster prevention functions are discussed and proposed by Tokida et al. (2007) based on the on-site investigations as for the damages of expressways and national highways in the 2004 Mid Niigata Prefecture Earthquake and the 2007 Noto Peninsula Earthquake.

Typical 8 items such as Item 1 to Item 8 to assess the structural vulnerability of each road embankment are selected and the estimation weight between each item and their detail ranks and their added scores to estimate the risk potential quantitatively can be recommended as follows.

Item 1 on the topographical conditions below embankments can be selected because the damage risk relates to the original terrain condition under the embankment such as ridge slope or stream. For example, the assessment rank and each relating score are assumed as shown in Fig. 2.

Rank-1 with score $=0$ in case of embankment located on large ridge slope

Rank-2 with score $=1$ in case of embankment located on small ridge slope

Rank-3 with score $=2$ in case of embankment located on slope in parallel 
Rank- 4 with score $=4$ in case of embankment located on small stream

Rank- 5 with score $=5$ in case of embankment located on large stream

The relative weight for Item 1 between 8 items is assumed to be 2, then the maximum value of the score $\mathrm{S} 1$ for Item 1 is 10 multiplying 2 by 5 .

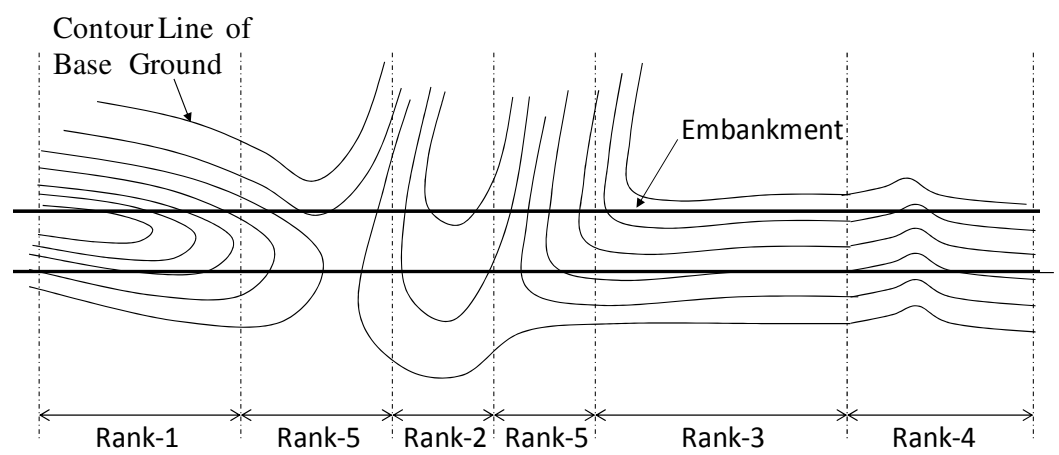

Fig. 2. Identification of topographical ranks for Item 1

Rank-1 with score $=0$ in case of embankment where the whole methods of A to E are applied.

Rank-2 with score $=1$ in case of embankment where both A and B methods are applied. Rank-3 with score $=2$ in case of embankment where the $C$ method is applied.

Rank-4 with score $=4$ in case of embankment where both $\mathrm{D}$ and $\mathrm{E}$ methods are applied. Rank- 5 with score $=5$ in case of embankment where no drain method is applied.

The above drain methods of A to E are identified as follows.

A is a method to drain the underground water from the mountain side with pipes or ditches laid on the base ground of embankments.

$B$ is a method to set the horizontal or vertical drain materials laid inside of embankments.

$\mathrm{C}$ is a method to drain the surface water from the mountain side with pipes and ditches laid inside of the embankments.

$\mathrm{D}$ is a method to drain the crest surface water with side ditches.

$E$ is a method to drain the slope surface water by side ditch.

The relative weight for Item 2 between 8 items is assumed to be 1, then the maximum value of the score S2 for Item 2 is 5 multiplying 1 by 5 .

Item 3 on the soil properties and quality of construction can be selected because the damage risk relates to the embankment soil properties or the quality of workmanship used during construction, such as compaction.

Rank-1 with score $=0$ in case of embankment where the embankment material is enough well, and good compaction or improvement is done.

Rank-2 with score $=3$ in case of embankment where the embankment material is normal and construction is normal.

Rank-3 with score $=5$ in case of embankment where the embankment material is not good and the construction condition is not good. 
The relative weight for Item 3 between 8 items is assumed to be 3, then the maximum value of the score S3 for Item 3 is 15 multiplying 3 by 5 .

Item 4 on the traverse structure of embankment can be selected because the damage risk relates to the traverse structure of the embankment, including the incline of the foundation ground, the configuration of the embankment, as shown in Fig. 3.

Rank- 1 with score $=0$ in case of embankment on flat base ground .

Rank-2 with score $=1$ in case of embankment on ups and downs base or ridge slope or one side cut and other side fill at the inclination base ground.

Rank-3 with score $=2$ in case of embankment on one side fill at the inclination base ground where the embankment edge is flat.

Rank-4 with score $=3$ in case of embankment on one side fill at the inclination base ground where the embankment edge slopes.
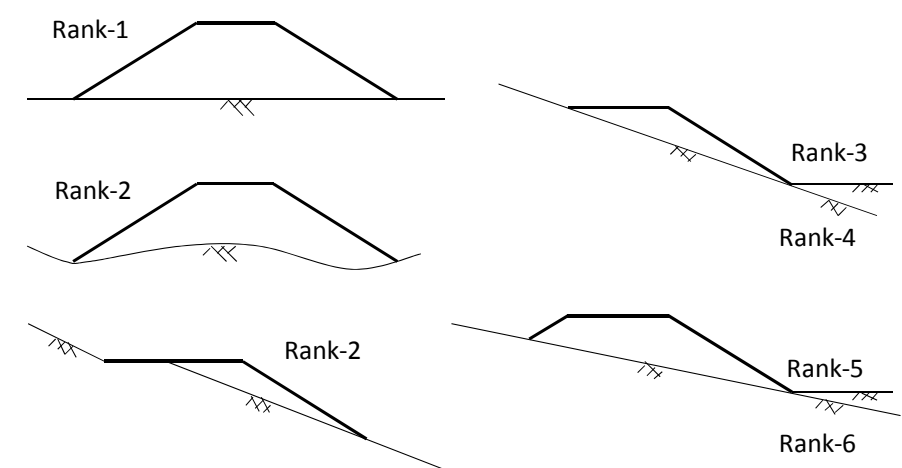

Fig. 3. Identification of traverse structures for Item 4

Rank-5 with score $=4$ in case of embankment on both side fills at the inclination base ground where the embankment edge is flat.

Rank- 6 with score $=5$ in case of embankment on both side fills at the inclination base ground where the embankment edge slopes.

The relative weight for Item 4 between 8 items is assumed to be 2, then the maximum value of rthe score $\mathrm{S} 4$ for Item 4 is 10 multiplying 2 by 5 .

Item 5 on the height of embankment can be selected because the occurrence and scale of damage risk relate to the embankment height as follows.

Rank-1 with score $=0$ in case of embankment which height is $4 \mathrm{~m}$ or less.

Rank-2 with score $=2$ in case of embankment which height is $8 \mathrm{~m}$ or less exceeding $4 \mathrm{~m}$.

Rank-3 with score $=4$ in case of embankment which height is $20 \mathrm{~m}$ or less exceeding $8 \mathrm{~m}$.

Rank- 4 with score $=5$ in case of embankment which height is 20 m excess.

The relative weight for Item 5 between 8 items is assumed to be 3, then the maximum value of the score $S 5$ for Item 5 is 15 multiplying 3 by 5 .

Item 6 on the inclination of embankment slope can be selected because the stability of embankment relates to the slope inclination as follows. 
Rank-1 with score $=0$ in case of embankment which slope inclination is below the standard one.

Rank-2 with score $=5$ in case of embankment which slope inclination exceeds the standard one.

The relative weight for Item 6 between 8 items is assumed to be 1, then the maximum value of the score $\mathrm{S} 6$ for Item 6 is 5 multiplying 1 by 5 .

Item 7 on the conditions reinforcing the embankment can be selected because the seismic and/or a certain improvements are effective to reduce damage of embankments as follows.

Rank-1 with score $=0$ in case of embankment reinforced based on the seismic design fully.

Rank-2 with score $=2$ in case of embankment where the retaining wall is applied.

Rank-3 with score $=4$ in case of embankment where the attached structures such as gabions are set.

Rank- 4 with score $=5$ in case of embankment where the countermeasures are not done.

The relative weight for Item 7 between 8 items is assumed to be 3, then the maximum value of the score $\mathrm{S} 7$ for Item 7 is 15 multiplying 3 by 5 .

Item 8 on the transformation history and/or present state of embankments can be selected because the past and/or present transformation indicates the sign and warning for the future damage occurrence. Four sub-items are selected to judge the risk of embankments considering the past and/or present conditions as follows.

Sub-Item-1 on the existence level of water spring on the slope and/or toe of embankment can be selected because the water conditions inside of embankments are most important. Each score of 0 to 5 are set considering the level of water spring and the relative weight is assumed to be 2, then the maximum value of the score S8- 1 for Sub-Item 1 is 10 multiplying 2 by 5 .

Sub-Item-2 on the transformation level of embankment crest such as cracks can be selected because the transformation is one of signs to be failed. Each score of 0 to 5 are set considering the level of transformation and the relative weight is assumed to be 0.6 , then the maximum value of the score S8-2 for Sub-Item 2 is 3 multiplying 0.6 by 5 .

Sub-Item-3 on the transformation level of embankment slope such as cracks can be selected because the transformation is one of signs to be failed. Each score of 0 to 5 are set considering the level of transformation and the relative weight is assumed to be 0.4 , then the maximum value of the score S8-3 for Sub-Item 3 is 2 multiplying 0.4 by 5 .

Sub-Item- 4 on the present performance of drainage system can be selected because the conditions of drainage system relate to the water conditions inside of embankments. Each score of 0 to 5 are set considering the level of transformation and the relative weight is assumed to be 2 , then the maximum value of the score S8-4 for Sub-Item 4 is 10 multiplying 2 by 5 .

The maximum value of the score 88 for Item 8 added each score of the above four sub-items gives 25. As a summary, the total score named SRP added from Item 1 to Item 8 which means the score of risk potential can be obtained in the Eq. (1) and scores and weight for each item and rank are summarized in Table 1.

$$
\mathrm{SRP}=\mathrm{S} 1+\mathrm{S} 2+\mathrm{S} 3+\mathrm{S} 4+\mathrm{S} 5+\mathrm{S} 6+\mathrm{S} 7+\mathrm{S} 8
$$




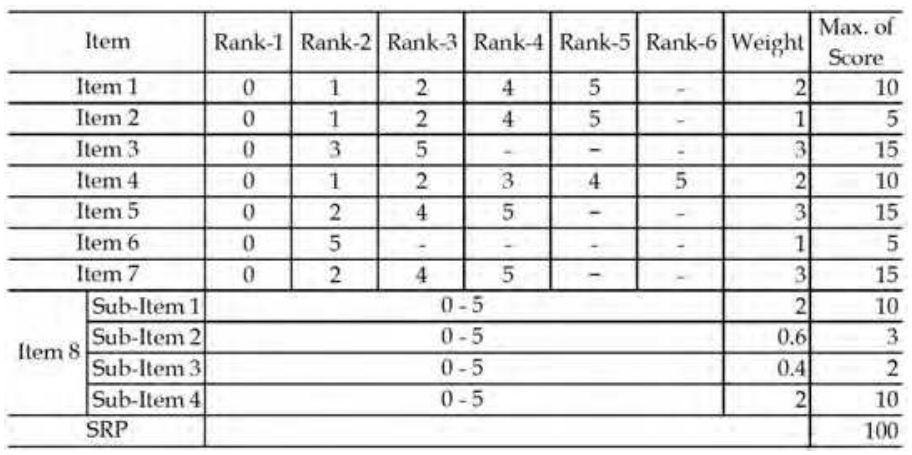

Table 1. Relation between item, rank, weight and scores

The value of SRP gives 0 to 100 and is named the evaluation value of seismic risk potential of an embankment at a certain site, i.e. means that when the value is larger, the damage potential can be indicated to become larger. Basing on the proposed assessment method with use of SRP, the seismic risk potential of a road embankment can be estimated easily, macroscopically and practically.

\subsection{Application of macroscopic assessment method}

The example of application of the macroscopic assessment method with the value of SRP can be obtained as shown in Fig. 4 where 13 damaged and 19 non-damaged embankments in the 2007 Noto Peninsula Earthquake are selected and compared each other.

The average score $\mu$ and standard deviation $\sigma$ are 60.7 and 8.2, respectively on the 19 nondamaged embankments. Then the score range of $\mu \pm \sigma$ is from 52.5 to 68.9. The average score and standard deviation are 75.2 and 4.8 , respectively on the 13 damaged embankments and then the score range of $\mu \pm \sigma$ is from 70.4 to 80.0 .

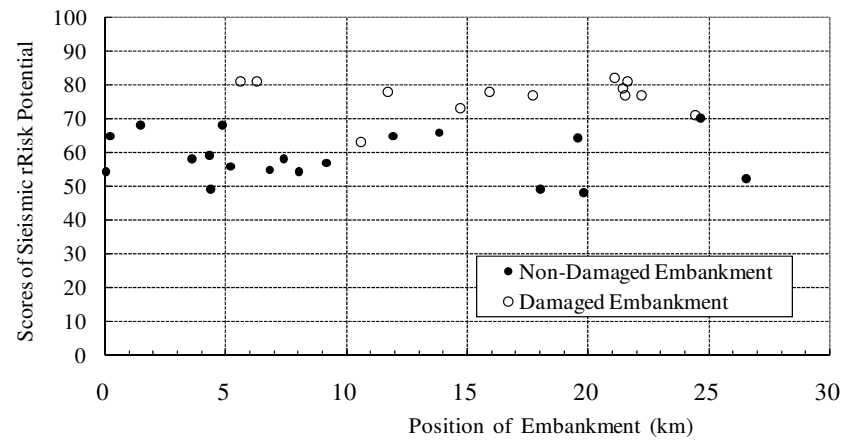

Fig. 4. Scores of seismic risk potential between non-damaged and damaged embankments in the 2007 Noto Peninsula Earthquake

Based on the results as shown in Fig. 4, the following lessons can be drawn to use the evaluation value of seismic risk potential practically. 
$0 \leqq \mathrm{SRP}<60$ : Seismic Potential of road embankment is very low or low.

$60 \leqq \mathrm{SRP}<70$ : Seismic Potential of road embankment is a little high or high.

$70 \leqq S R P \leqq 100$ : Seismic potential of road embankment is high or very high.

\section{Performance-based design concept for road embankment}

Recently the new design concept, i.e., performance-based design is necessary for reasonable and economical design of road embankments against severe earthquakes. In this Chapter, four design concepts considering the seismic performance of road embankments are proposed, and the criterion to judge the damage level of settlements or sliding displacements is introduced.

\subsection{Concepts based on performance-based design}

Comparing the severe damage of road embankment shown in Photo. 1(b) with the slight damage shown in Photo. 2(a), it can be hinted to control the position of the sliding plane occurred not to reach to the traffic lane, then to keep the traffic performance at a certain level just after an earthquake. This fundamental design concept was proposed by Tokida et al. (2007) and named "Sliding Failure Control Method". The control of the sliding failure aims to change the positon of sliding plane and/or to decrease the sliding displacement occurred during earthquakes not to disturb the traffic performance perfectly. Furthermore, as shown in Fig. 5, four specific design concepts such as "Crest Reinforcement Structure", "Barrier Reinforcement Structure", "Artificial Reinforcement Structure" and "Toe Reinforcement Structure" can be proposed to achieve the fundamental design concept. The performance of each reinforcement structure is as follows.

Crest Reinforcement Structure aims to reinforce the crest of embankment partially with use of geotexstile etc. and not to occur the sliding plane and decrease the sliding displacement on the top of the embankment, then maintain the traffic performance enough just after an earthquake. Toe Reinforcement Structure aims to reinforce the toe of embankment to control the sliding plane and decrease the sliding displacement. Artificial Reinforcement Structure aims to control the sliding plane by improving the embankment body stiffly as shown in Fig. 5 to control the sliding plane not to reach the traffic lane. Barrier Reinforcement Structure aims to control the position of the sliding plane with use of sheet piles etc. and not to occur at the traffic lane, then maintain the traffic performance enough just after an earthquake.

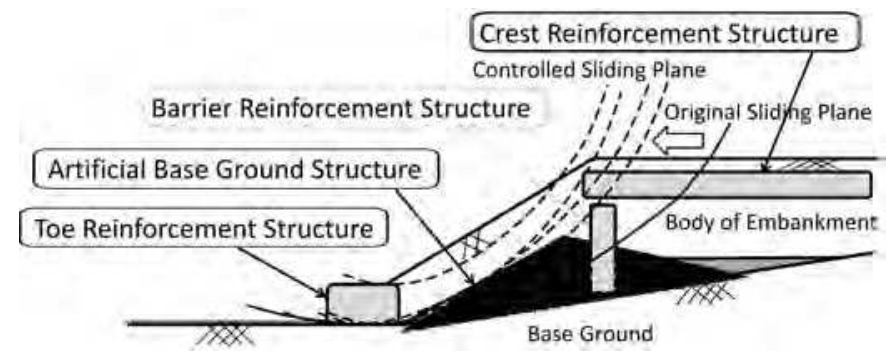

Fig. 5. Typical concepts proposed for performance-based design of road embankment

As mentioned above, these four reinforcing structures are constructed partially and then economically. 


\subsection{Performance level for seismic design of road embankment}

For the performance-based design of road embankments, the performance level as the purpose of the seismic design is necessary to be set. Because the performance level for road embankments has not been clarified in Japan, Tokida et al. (2007) conducted the driving tests to investigate the relation between the step height and the driving velocity through the steps to know the limit height of steps occurred at the pavement surface during earthquakes as shown in Fig. 6(a).

The test results are summarized in Fig. 6(b) which shows the limit height of steps able to drive through without repair, relating to some conditions of the small or large vehicle size, the emergency or personal vehicle and the velocity of vehicles driving through the steps such as almost stop (0 to $10 \mathrm{~km} / \mathrm{h}$ ), slow down (15 to $20 \mathrm{~km} / \mathrm{h}$ ) and normal (for example, 60 to $80 \mathrm{~km} / \mathrm{h}$ ).

Based on the driving test results such as in Fig.6(b), the performance level considering traffic performance just after an earthquake can be proposed as shown Table 2. The performance levels are classified into four types as follows.

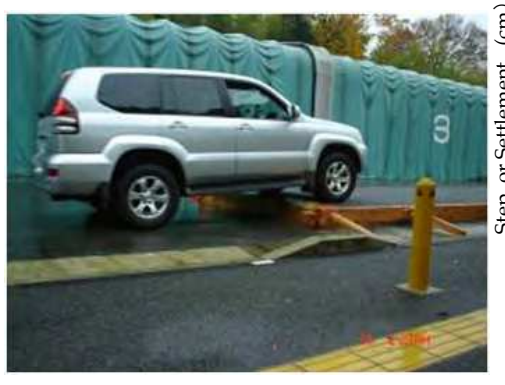

(a) Driving test

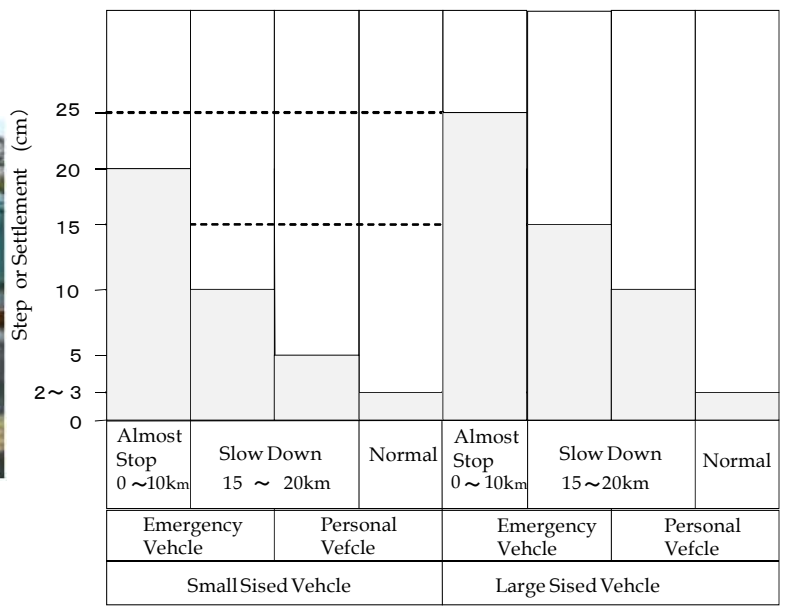

(b) Relations between step and driving velocity

Fig. 6. Driving tests and results

\begin{tabular}{c|c|c|c|c|c}
\hline \multirow{2}{*}{$\begin{array}{c}\text { Performance } \\
\text { Level }\end{array}$} & \multirow{2}{*}{$\begin{array}{c}\text { Traffic Performance } \\
\text { Just After EQ. }\end{array}$} & Step of Road Surface & Sliding Failure & \multicolumn{2}{|c}{ Factors to Estimate Damage } \\
\cline { 3 - 6 } & Maintained Normally & $\begin{array}{c}\text { Step Height Smaller } \\
\text { than } 2 \sim 3 \mathrm{~cm}\end{array}$ & Not Slid & Not Settled & Longitudinal \\
\hline \multirow{2}{*}{2} & $\begin{array}{c}\text { Decreased a Little } \\
\text { and Recovered Easily }\end{array}$ & $\begin{array}{c}\text { Step Height Larger than } \\
2 \sim 3 \mathrm{~cm} \text { and Smaller } \\
\text { than } 20 \sim 25 \mathrm{~cm}\end{array}$ & $\begin{array}{c}\text { Slid at Shoulder or } \\
\text { Slope Partially }\end{array}$ & $\begin{array}{c}\text { Settled Small and } \\
\text { Uniformly }\end{array}$ & $\begin{array}{c}\text { Settled Small and } \\
\text { Uniformly }\end{array}$ \\
\hline \multirow{2}{*}{4} & $\begin{array}{c}\text { Decreased and } \\
\text { Difficult a Little to } \\
\text { Recover }\end{array}$ & $\begin{array}{c}\text { Step Height Larger than } \\
20 \sim 25 \mathrm{~cm} \text { and Smaller } \\
\text { than } 50 \mathrm{~cm}\end{array}$ & $\begin{array}{c}\text { Slid at One Traffic } \\
\text { Lane Partially }\end{array}$ & $\begin{array}{c}\text { Settled Small and } \\
\text { Not Uniformly }\end{array}$ & $\begin{array}{c}\text { Settled Small and } \\
\text { Not Uniformly }\end{array}$ \\
\hline & $\begin{array}{c}\text { Decreased and } \\
\text { Difficult to Recover }\end{array}$ & $\begin{array}{c}\text { Step Height Larger than } \\
50 \mathrm{~cm}\end{array}$ & $\begin{array}{c}\text { Slid at Two Traffic } \\
\text { Lanes Totally }\end{array}$ & $\begin{array}{c}\text { Settled Largely and } \\
\text { Not Uniformly }\end{array}$ & $\begin{array}{c}\text { Settled Largely and } \\
\text { Not Uniformly }\end{array}$ \\
\hline
\end{tabular}

Table 2. Performance level considering traffic performance just after earthquake 
Level 1: The traffic performance can be maintained normally just after an earthquake, because the steps occurred are smaller than 2 to $3 \mathrm{~cm}$.

Level 2: The traffic performance is decreased a little just an earthquake, but can be recovered rapidly and easily, because the steps occurred are smaller than 20 to $25 \mathrm{~cm}$ where the vehicles can be go through the steps as shown in Fig. 6 (a).

Level 3: The traffic performance is decreased just an earthquake and difficult a little to recover soon, because the steps occurred are larger than 20 to $25 \mathrm{~cm}$ and smaller than $50 \mathrm{~cm}$.

Level 4: The traffic performance is decreased just an earthquake and it takes long time to recover, because the steps occurred are larger than $50 \mathrm{~cm}$.

As shown above, Table 2 can be applied to set the objective performance level of the sliding failure of road embankments in the design of both new embankments and existing ones in the future.

\section{Analytical estimation of sliding failure of road embankment}

It is necessary to estimate the damage level of road embankments for the performance-based design. In this chapter, the typical analytical method named Newmark Method (Tateyama et al., 1998) modified the Original Newmark Method (Newmark, 1965) for calculating the sliding displacement of road embankments during earthquakes is shown and its application is discussed based on the damaged examples of road embankments in the past earthquakes shown in Chapter 2.

Fig. 7 is the example appling the Newmark Method to the embankment damaged during the Noto Peninsula Earthquake in 2007. The ground motion inputted at the bottom of the embankment model shown in Fig. 7(b) is revised the maximum acceleration from the ground acceleration of 580gal in the East-West direction shown in Fig. 7(a) which was observed at Togi City set by National Research Institute for Earth Science and Disaster Prevention (NIED) to the one of 500gal. As known in Fig. 7(b), the position of the sliding plane measured after the earthquake is almost similar to the analytical one. Furthermore, the measured sliding displacement at the crest of the embankment is $10.9 \mathrm{~m}$ and similar to the $9.7 \mathrm{~m}$ measured.

In this case study, the sliding failure such as the position of the sliding plane and the sliding displacement estimated with use of the Newmark Method is well estimated analytically.

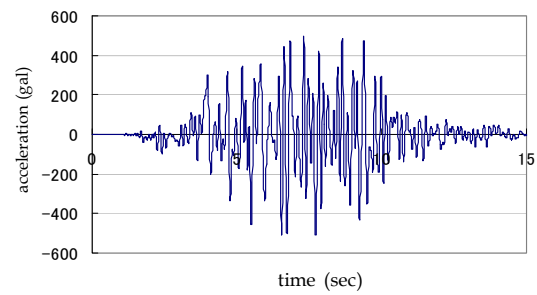

(a) Observed E-W ground motion at Togi

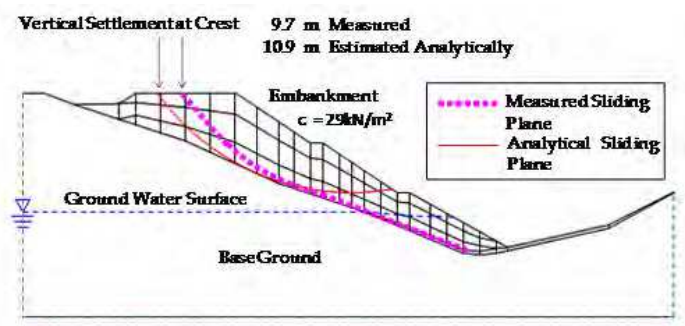

(b) Measured and analytical sliding failure

Fig. 7. Example of application of Newmark Method 


\section{Performance-based countermeasures for road embankment}

Several seismic countermeasures are proposed concretely and their applications are discussed. In the case of the Crest Reinforcement Structure, the crest of road embankments is reinforced with use of geosynthetics and its application is verified based on the static large-scaled model test, the dynamic centrifuge test and the static and dynamic analyses quantitatively and/or qualitatively. In case of the Toe Reinforcement Structure, the toe of road embankments is reinforced by large-scaled gabions and its application is verified based on analyses qualitatively. In case of the Artificial Base-ground Structure, the body of road embankments is improved partially to construct the artificial base ground where the sliding plane is assumed not to be occurred and its application is verified based on analyses qualitatively. In case of the Barrier Reinforcement Structure, the barrier structures such as sheet piles and underground walls may be constructed practically and its application is verified based on the centrifuge test quantitatively.

\subsection{Crest reinforcement structure with geosynthetics}

Fig. 8 shows the example of the Crest Reinforcement Structure with use of the geosynthetics. This structure can be applied to both existing and newly constructed embankments. In the case of the existing embankment, the sheets of geosynthetics are installed at the overall crest of the embankment as shown in Fig. 8 based on the excavation and the re-pavement, or around the shoulder of the embankment partially. The reinforcing work is necessary to be paid attention to reduce the effects on the traffic performance as little as possible. On the other hand, in the case of newly construction, the sheets of geosynthetics can be easily set inside of the embankment. The practical applications of the crest reinforcement structure with use of geosynthetics have been discussed and clarified as follows.

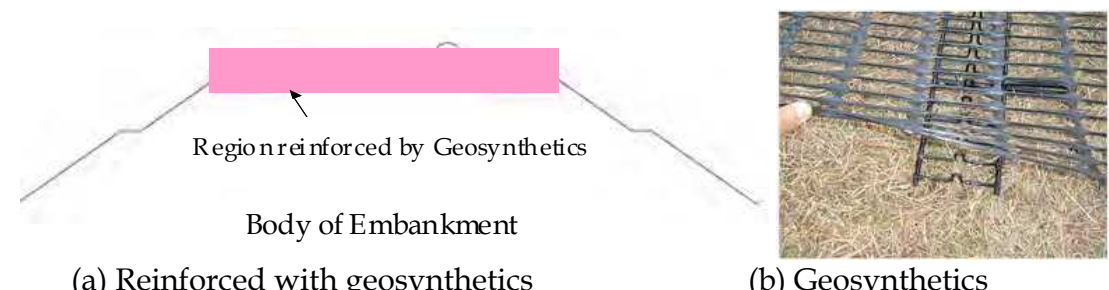

Fig. 8. Example of crest reinforcement structure

\subsubsection{Static large-scaled model test}

The large-scaled embankment model is constructed in extension of $3.6 \mathrm{~m}$, depth of $1.8 \mathrm{~m}$ and height of $4.1 \mathrm{~m}$, which is surrounded by both wooden panels and sandbags shown Fig. 9(a). As shown in Fig. 9(b), the model is divided into 4 reinforcement patterns. In each pattern, the overburden surface layer with the thickness of $50 \mathrm{~cm}$ are set at the crest of the embankment model. Pattern 1 is the fundamental model without reinforcement. In cases of Pattern 2 and Pattern 3, 5 layers with the thickness of $30 \mathrm{~cm}$ in length of $1 \mathrm{~m}$ and $2 \mathrm{~m}$, respectively are reinforced with geosynthetics connected by metal fittings each other. In case of Pattern 4, the embankment body is lapped with the geosynthetics which is tied with 
ropes. The soil properties are shown in Table 3 and the fine aggregate without fine-grained fraction of the wet density of $\gamma_{t}=18 \mathrm{kN} / \mathrm{m}^{3}$ which tends to occur a collapse easily. The static failure of the reinforced embankment model is planned to be occurred by removing the panels and sandbags.
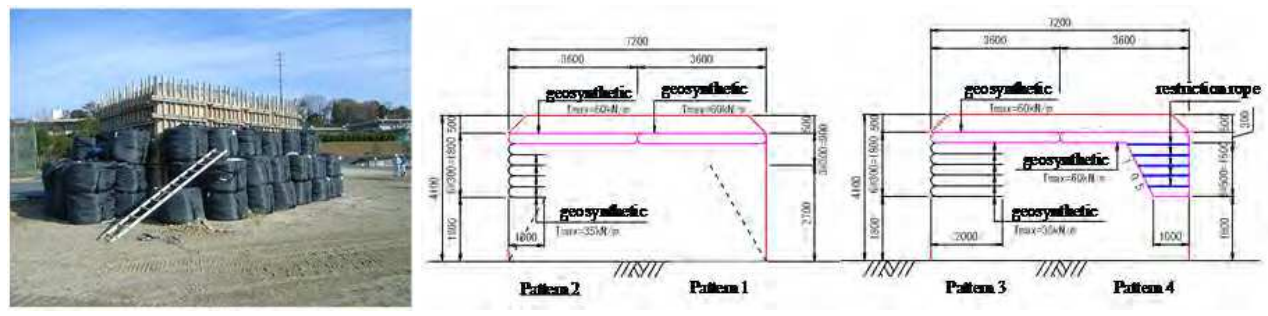

(a) View of embankment model

(b) 4 patterns of reinforced embankment models (unit:nm)

Fig. 9. Large-scalled embankment model in field test

The collapse mode of each reinforced embankment model is illustrated in Fig. 10(a). In case of Pattern 1, the large sliding failure occurred at the whole area of the embankment body beneath the surface layers. In case of Patterns 2 and 3, each deformation of the embankment body is smaller than Pattern 1. Moreover, the deformation of the embankment model in case of Pattern 3 with a longer reinforcement than that of Pattern 2 became smaller than that of Pattern 2. The difference of each damage level can be known in Fig. 10(b) which shows the side plane conditions and the surface condition of the crest of the embankment models. In case of Pattern 4, the whole reinforced part slid down severely because of the weight of the reinforced body.

\begin{tabular}{l|l|l}
\hline Geosynthetics & $\begin{array}{l}\text { Tensile strength }: 35(\mathrm{kN} / \mathrm{m}), 60(\mathrm{kN} / \mathrm{m}) \\
\text { Elongation : } 5.0(\%)\end{array}$ & $\begin{array}{l}\text { Core : aramid fiber } \\
\text { Covering : polyethylene }\end{array}$ \\
\hline Metal fittings & $\phi 3 \mathrm{~mm}, 6 \mathrm{~mm}$ & Ordinary iron wire \\
\hline Restriction rope & $\begin{array}{l}\text { Tensile strength }: 22(\mathrm{kN}) \\
\text { Elongation : } 40 \%\end{array}$ & $\begin{array}{l}\text { Polyester spinning rope } \\
\phi 12 \mathrm{~mm}\end{array}$ \\
\hline Embankment & $\gamma=18 \mathrm{kN} / \mathrm{m}^{3}, \mathrm{c}=0 \mathrm{kN} / \mathrm{m}^{2}, \phi=40^{\circ}$ \\
\hline
\end{tabular}

Table 3. Properties of test material 

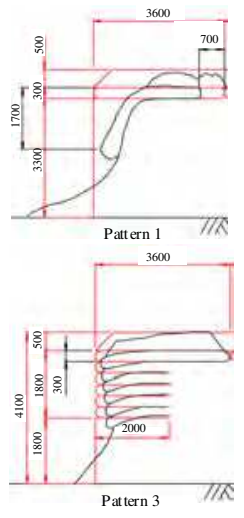

(a) Deformation of models (unit: $\mathrm{mm}$ )

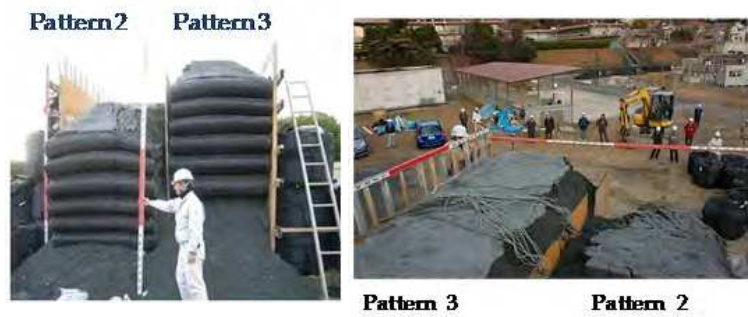

(b) Difference of Settlement Level

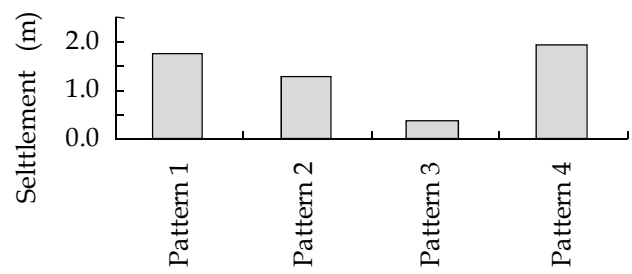

(c) Comparison of settlement at shoulder

Fig. 10. Comparison of damage level between different reinforcement patterns

The test results on the settlements at the shoulders of each embankment model can be summarized in Fig. 10(c) where the settlements of Pattern 1, Pattern 2, Pattern 3 and Pattern 4 are $1.7 \mathrm{~m}, 1.3 \mathrm{~m}, 0.3 \mathrm{~m}$ and $1.9 \mathrm{~m}$, respectively. Therefore, it can be indicated that Pattern 3 where the horizontal length of the geosynthetics is set deeper than the estimated sliding plane is most effective to keep the shape of the embankment during an earthquake.

\subsubsection{Dynamic centrifuge model test}

Applying the steel container which is $900 \mathrm{~mm}$ wide, $300 \mathrm{~mm}$ thick and $280 \mathrm{~mm}$ high as shown in Fig. 11, several centrifuge tests are carried out under the acceleration of $30 \mathrm{~g}$. A half-sized embankment on the solid base ground is made using the DL clay and silicon oil to adjust the water content to $5 \%$ in height of $290 \mathrm{~mm}$ which corresponds to the actual height of $8.7 \mathrm{~m}$. The density of total fill is $1.52 \mathrm{~g} / \mathrm{cm}$ and the shear wave velocity of embankment model measured is $158 \mathrm{~m} / \mathrm{sec}$ in $1 \mathrm{~g}$ and $185 \mathrm{~m} / \mathrm{sec}$ in $30 \mathrm{~g}$. As shown in Fig. 11, the horizontal and vertical accelerometers are installed in three sites to measure the input acceleration on the bottom of soil container and response acceleration of embankment model near the toe of slope in height of $90 \mathrm{~mm}$ and under the edge of slope in height of $230 \mathrm{~mm}$ from the bottom. To measure the final residual deformation of model, several colored sand columns are installed into the central cross section of model from the surface in the interval of $60 \mathrm{~mm}$ and several markers put at the surface of the embankment in the interval of $50 \mathrm{~mm}$. Furthermore, two thin plates with the thickness of $0.3 \mathrm{~mm}$ on 
which the strain gauges are pasted on both sides are placed in the upper and central parts of embankment to investigate the failure mechanism.

Fig. 12(a) shows the cross section cut at the center of the embankment model which is not reinforced and slid largely by the inputted motion with the maximum acceleration of 488gal. Fig. 12(b) compares the initial and slid shapes of the embankment model drawn by markers located at the surface and the colored sands columns. Comparing the positions of markers before and after dynamic motions in Fig. 12(b), it can be seen that however the embankment body around the shoulder is disturbed according to the sliding, the sliding body is driven over all because the displacement of markers at the shoulder of $89 \mathrm{~mm}$ and the one along the slope of $87 \mathrm{~mm}$ are almost same. On the other hand, the vertical settlement at the shoulder is $65 \mathrm{~mm}$ which is converted to $1.95 \mathrm{~m}$ at the field. As mentioned above, it can be clarified that it's possible to reproduce the dynamic sliding plane artificially by the centrifuge test.
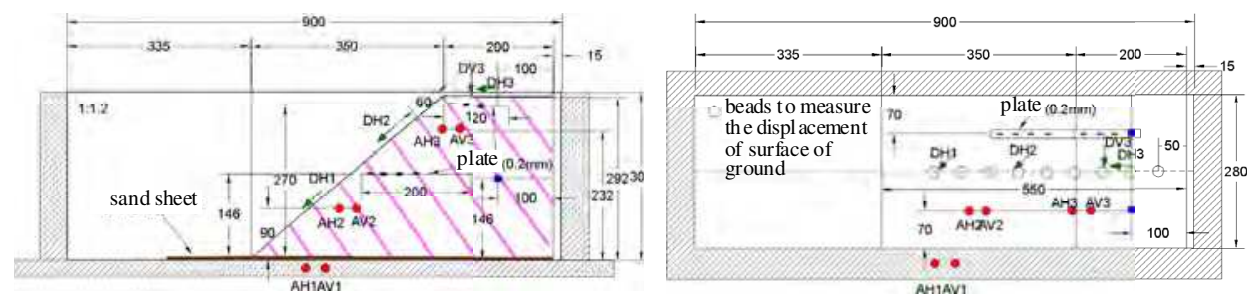

$$
\begin{array}{|ll|}
\hline \text { bender element } & - \text { color sand } \\
\text { acc erometer } & \rightarrow \text { laser displacement } \\
\text { - strain gauge } & \text { sensor } \\
\hline
\end{array}
$$

(a) Cross sectrion (unit: $\mathrm{mm}$ )

(b) Plane section (unit:mm)

Fig. 11. Embankment model and measurement for dynamic centrifuge test

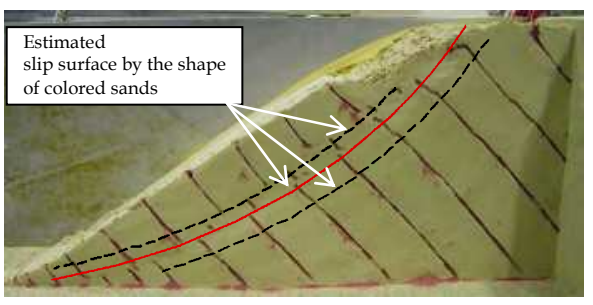

(a) Sliding plane occurred

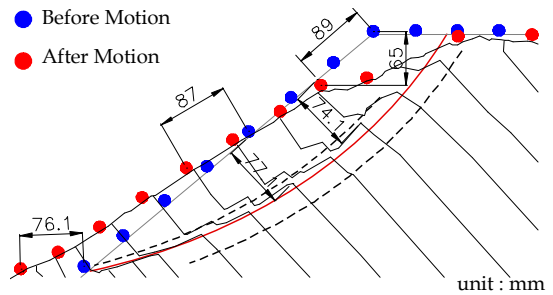

(b) Before and after dynamic motion

Fig. 12. Sliding failure in case of non-reinforced model

As shown in Fig. 13, four types of embankment models which are aimed the Crest Reinforcement Structure reinforced with changing the numbers of reinforced layers and the installed length of geosynthetics. The embankment modei in Case 1 is reinforced at the whole surface of crest with two layers by three long geosynthetics sheets which are fixed with the side wall. The one in Case 2 is reinforced with one layer by two long geosynthetics sheets and two layers with two short one which are set more deeply than the estimated sliding plane occurred in the case of nonreinforced embankment model shown in Fig. 12. 
These two cases are supposed for the newly constructed embankment or the existing one to reinforce wholly. The ones in Case 3 and Case 4 are reinforced with three layers by four short geosynthetics sheets and two layers with three short ones, respectively. These two cases are supposed to apply to the existing embankment not to disturb the traffic activity under construction works.

In the above four cases, the thickness of both long and short reinforced layer is set to be $30 \mathrm{~mm}$ which scale is $0.9 \mathrm{~m}$ in the field. To ensure the total performance of reinforced zone, geosynthetics sheets are connected with each other at the surface of slope.

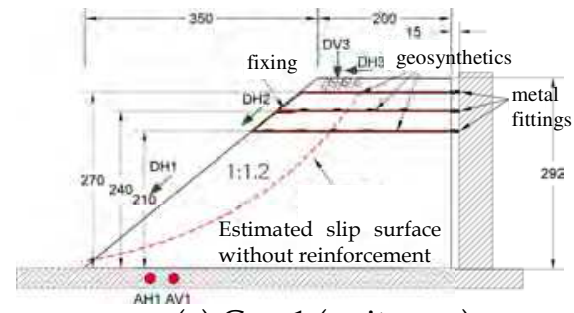

(a) Case1 (unit: $\mathrm{mm}$ )

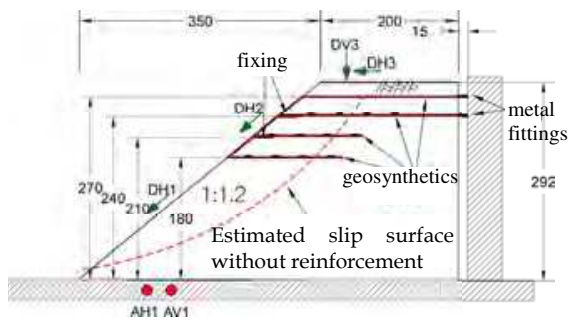

(b) Case2 (unit: $\mathrm{mm}$ )

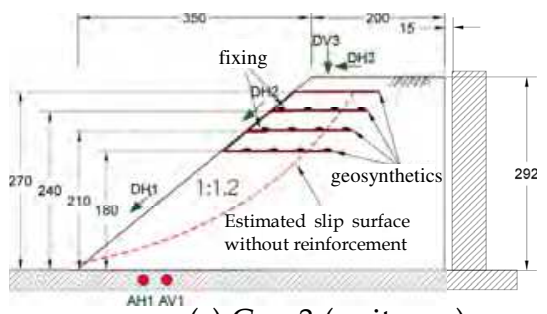

(c) Case3 (unit:mm)

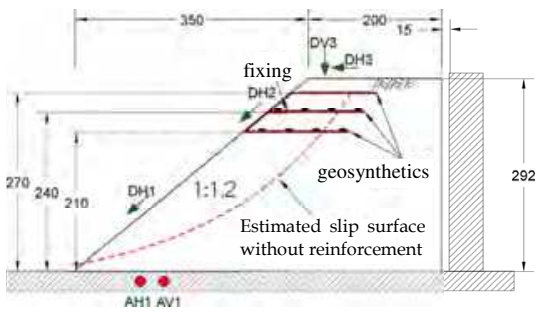

(d) Case4 (unit:mm)

Fig. 13. Embankment Model Reinforced with Geosynthetics

Fig. 14 compares the slid conditions between four cases measured at the central cross section after inputting the sinusoidal motion with the maximum acceleration of about $500 \mathrm{gal}$. It can be indicated qualitatively as follows based on the results of Fig. 14.

Case 1: The deformation on the crest of embankment is small and the sliding occurs at the area lower than the reinforced zone including the lower side of reinforced zone. The volume of sliding area is larger than that of Case 2.

Case 2: The deformation on the crest of embankment is small extremely and the sliding occurs at only the area lower than the reinforced zone which is not affected by the sliding. The effectiveness of the reinforcement can be known clearly in Photo. 10

Case 3: The deformation on the crest of embankment is very small and the sliding occurs at only the area lower than the reinforced zone which is not affected by the sliding.

Case 4: The deformation on the crest of embankment is occurred a little and the sliding occurs not only at the area lower than the reinforced zone but also at the boundary of reinforced zone which is reached to the surface of the crest. 


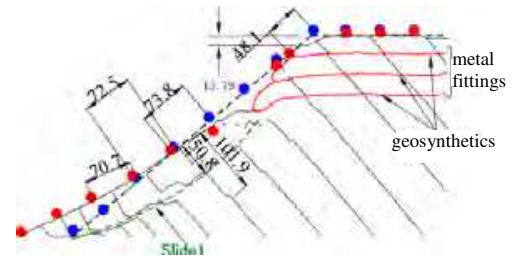

(a) Case1 (unit:mm)

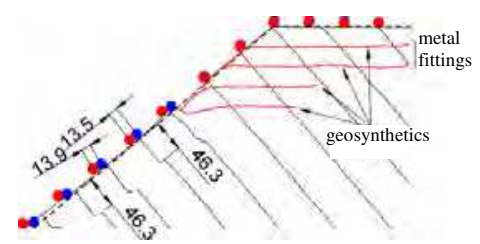

(b) Case2 (unit:mm)

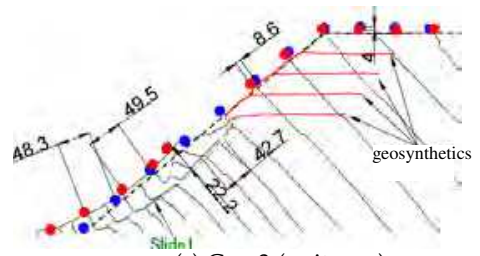

(c) Case3 (unit:mm)

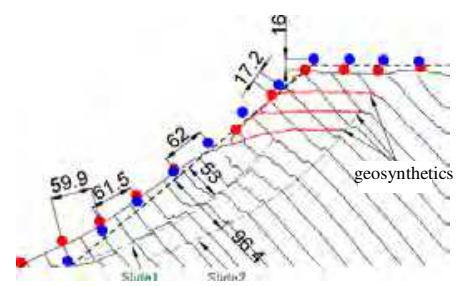

(d) Case4 (unit:mm)

Fig. 14. Sliding failure in case of reinforced model with geosynthetics

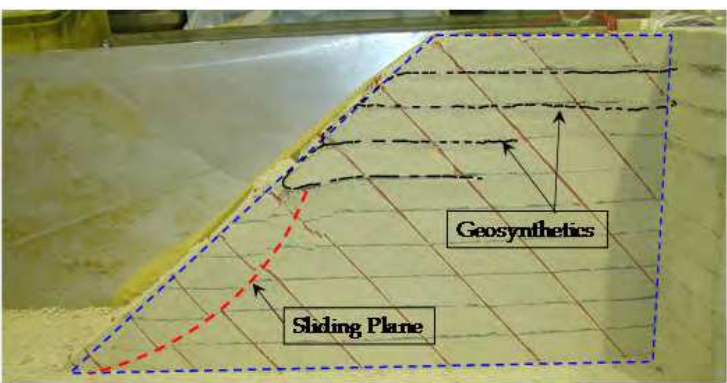

(a) Sliding at cross section

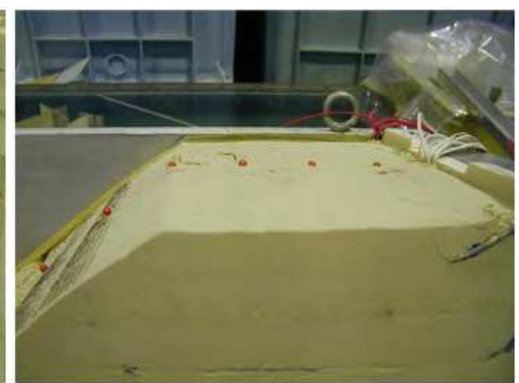

(b) Condition at crest

Photo 10. Overview of deformation of reinforced embankment model in Case 2

The residual displacements measured at the shoulder and upper and lower slope of the four reinforced models comparing with the non-reinforced one in Fig. 12 are summarized in Fig. 15. Compared the reinforced models with the one without reinforcement, both horizontal and vertical residual displacements at the shoulder of the embankment model are decreased greatly in the whole reinforced models as shown in Fig. 15(a). Furthermore, the residual displacements along the upper-side slope are also decreased greatly as shown in Fig. 15(b).

However the residual displacements along the lower-side slope are not so smaller than that without reinforcement, it is not an important problem because the slid zone below the reinforced zone doesn't affect directly on the traffic performance will be repaired easily later.

As mentioned above, it can be indicated that the Crest Reinforcement Method with geosynthetics sheets is very effective for both newly constructed embankment and existing ones to get minimum traffic performance just after earthquakes. Some lessons can be obtained that the number of reinforced layers is very important for both long sheets and short sheets and the short sheets should be set deeper than the estimated sliding plane and almost fixed at the inside end. 


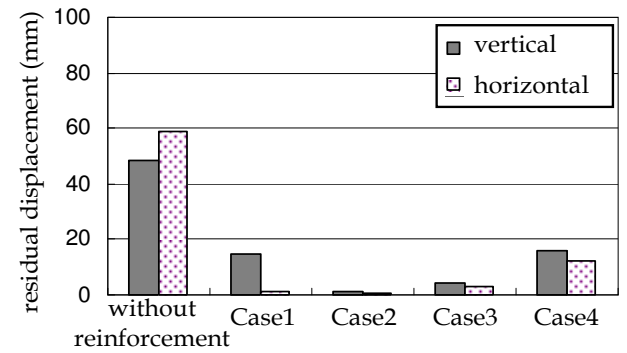

(a) At shoulder

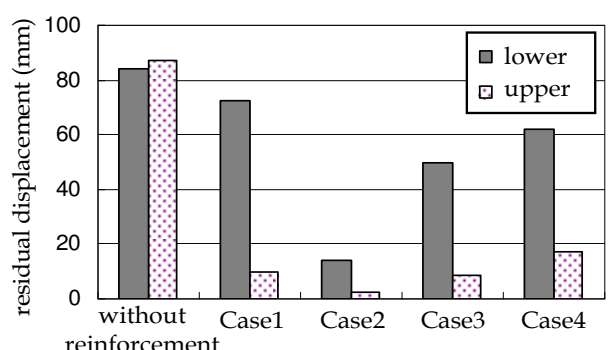

(b) At lower or upper slope

Fig. 15. Comparison of Residual Displacement

\subsubsection{Analytical estimation}

The example of analytical application of the Crest Reinforcement Structure with geosynthetics should be referred to Chapter 6.3.

\subsubsection{Practical application in field}

The Crest Reinforcement Structure has been applied at a certain site where the road embankment approaching to the other construction site is constructed temporally as shown in Fig. 16(a). The maximum height of the embankment is $20 \mathrm{~m}$ and the slope ratio of that is 1:1.8. The soil materials used for the embankment body are classified into the silty clay with high natural water content of $50 \%$ and the average cohesion is $12.8 \mathrm{kN} / \mathrm{m}^{2}$.as shown in Fig. 16(b). Therefore, because the embankment body is necessary to be improved to achieve the sliding safety factor of 1.2 in general conditions, the embankment body is improved to the shear strength of $74 \mathrm{kN} / \mathrm{m}^{2}$ with cements. Furthermore, the Crest Reinforcement Structure with geosynthetics as shown in Fig. 16(a) is designed additionally.

As shown in Fig. 16(a), one reinforced layer with two long sheets of $9 \mathrm{~m}$ and two reinforced layers with two short sheets of $2 \mathrm{~m}$ which are similar to the Case 2 in the centrifuge test in Fig. 13. The thickness of each layer is $0.5 \mathrm{~m}$. However the seismic design hasn't been applied in this case, it's very important that this case is the first trial to apply the Crest Reinforcement Structure in Japan as shown in Fig. 16(b) and can be obtained important lessons to construct the structures in the field.

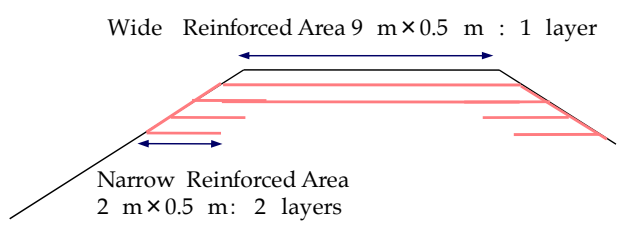

(a) Design condition for cross section

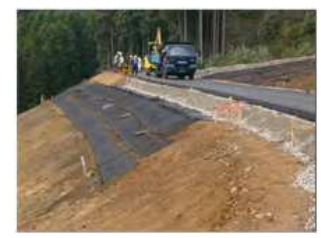

(b) Completed embankment

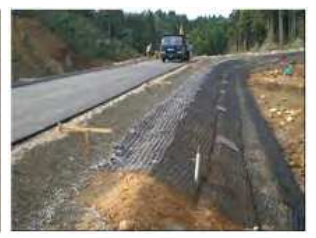

Fig. 16. Application of crest reinforcement structure to actual road

\subsection{Toe reinforcement structure}

In Japan, the groundwater in road embankments causes severe damage of road embankments due to earthquakes, and a lot of embankments to be damaged have been 
reported in recent years. A large-scale gabion is given as a typical structure of the Toe Reinforcement Structure in this Chapter. As for the large-scale gabion, the merits to apply it are low-cost, good construction workability, and there are a lot of actual results in the field as the disaster restoration method for the purpose of drainage as shown in Photo.11 (a).

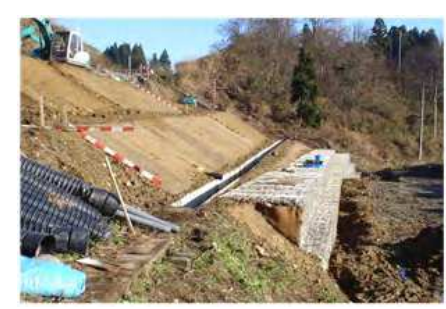

(a) Disaster restoration

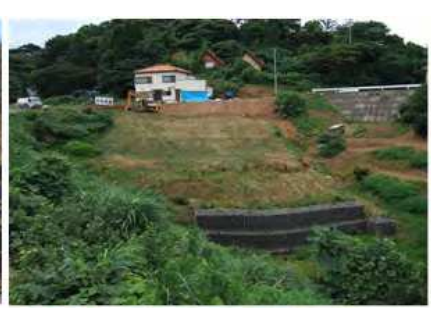

(b) Moved gabions and occurred sliding

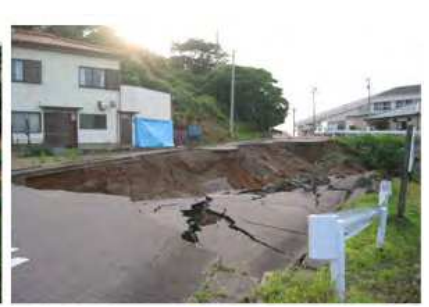

Photo 11. Application of large-scaled gabion at present

However the gabions were set only for drainage in advance, they could not work against the seismic motion as shown in Fig. 11(b). Then it is necessary and effective to apply the largescale gabions for not only drainage but also reinforcement of the embankment.

For the reinforcing design of gabions, friction factors are necessary to be estimated. As for the friction factors between the base ground and the superstructure, Table 4 summarizes the static friction factors applied to the erosion cntrol dam, the retaining wall and the river wall in Japan based on Erosion Control \& Land Slide Technical Center (2009), Japan Road Association (1999) and Japan River Association (1997), respectively. However Table 4 can be applied for the road embankment design, the drag force tests are tried as follows to investigate both static and dynamic friction factors for road embankments in detail.

\begin{tabular}{|c|c|c|c|c|c|c|}
\hline \multirow{3}{*}{\multicolumn{2}{|c|}{$\begin{array}{c}\text { Condition of Base } \\
\text { Ground }\end{array}$}} & \multicolumn{5}{|c|}{ Super-structure Condition on Base Ground } \\
\hline & & \multicolumn{2}{|c|}{ Erosion Control Dam } & \multicolumn{2}{|c|}{ Retaining Wall } & \multirow{2}{*}{$\begin{array}{c}\text { River Wall } \\
\begin{array}{c}\text { Concrete Block or } \\
\text { Gabion }\end{array}\end{array}$} \\
\hline & & $\begin{array}{l}\text { Gravel or Soil } \\
\qquad\left(\varphi_{A}\right)\end{array}$ & Concrete & $\begin{array}{c}\text { Concrete } \\
\text { worked at Site }\end{array}$ & $\begin{array}{l}\text { Pre-casted } \\
\text { Concrete }\end{array}$ & \\
\hline Rock & \multirow{5}{*}{$\left(\varphi_{\mathrm{B}}\right)$} & \multirow{5}{*}{ 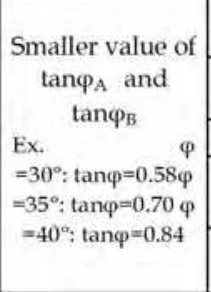 } & $0.7 \sim 1.2$ & $\tan \varphi_{B}$ or 0.7 & \multirow{4}{*}{$\begin{array}{c}\tan \varphi_{\mathrm{B}} \text { or } 0.6 \\
\leqq 0.6\end{array}$} & - \\
\hline $\begin{array}{c}\text { Blocked Rock, } \\
\text { Stone }\end{array}$ & & & 0.7 & \multirow[t]{2}{*}{$\tan \varphi_{B}$ or 0.6} & & - \\
\hline Gravel Layer & & & 0.6 & & & - \\
\hline Sand Layer & & & 0.55 & $\tan \varphi_{B}$ or 0.6 & & \multirow{2}{*}{0.65} \\
\hline Clay Layer & & & 0.45 & $\tan \varphi_{\mathrm{B}}$ or 0.5 & $\begin{array}{c}\tan \varphi_{B} \text { or } 0.5 \\
\leqq 0.6\end{array}$ & \\
\hline
\end{tabular}

Table 4. Friction coefficients applied to several structures in Japan

\subsubsection{Friction coefficient of large-scaled gabion}

The field tests using full-scaled gabions were carried out and the effects on friction factors by the mesh-structure, the ground surface condition and the weight and/or load of gabions 
are discussed. Photo. 12 shows the three types of the conditions at the ground surface where the gabions are placed: a mat-placed ground, a sandy ground and a crushed-stone-layered ground, respectively. The sheet of a mat is permeable and possible to be set at the bottom of gabions to prevent fine soil particles to be flown out from the beneath the ground.

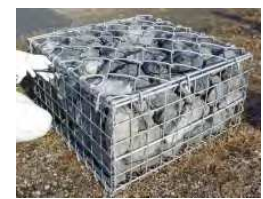

(a) Diamond-shaped (b

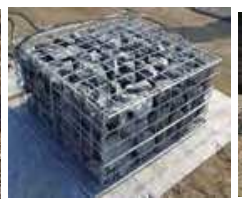

(b) Grid-shaped

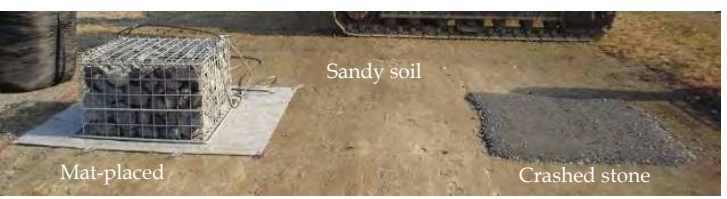

(c) Ground surface condition to place gabions

Photo 12. Structure of gabion and ground surface condition

\begin{tabular}{|c|c|c|c|c|}
\hline \multirow{2}{*}{ Structure of Gabion } & \multirow{2}{*}{$\begin{array}{c}\text { Static Friction Coefficient: SFC } \\
\text { Dynamic Friction Coefficient : } \\
\text { DFC }\end{array}$} & \multicolumn{3}{|c|}{ Base Ground Condition } \\
\hline & & Crushed stone & Sandy soil & Mat-placed \\
\hline \multirow{2}{*}{$\begin{array}{l}\text { Steel-made assembly mesh } \\
\text { (diamond-shaped wire-mesh) }\end{array}$} & SFC & 0.64 & 0.61 & 0.51 \\
\hline & DFC & 0.59 & 0.54 & 0.48 \\
\hline \multirow{2}{*}{$\begin{array}{l}\text { Steel-made assembly mesh } \\
\text { (grid-shaped wire-mesh) }\end{array}$} & SFC & 0.79 & 0.77 & 0.63 \\
\hline & DFC & 0.74 & 0.68 & 0.55 \\
\hline
\end{tabular}

Table 5. Static and dynamic friction coefficient

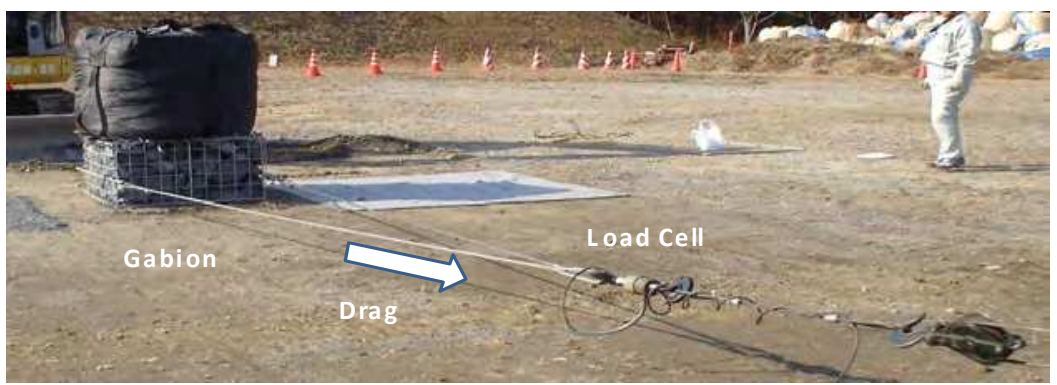

Photo 13. Typical method to drag gabion and measure drag-Load

Furthermore, three types of the weight and/or load condition are considered. The weight at Stage 1: $7.487 \mathrm{kN}$ are the same with that of the practical gabion and each weight at Stage 2: $15.249 \mathrm{kN}$ and at Stage 3: $21.619 \mathrm{kN}$ is about twice and three times the weight of the practical one, respectively. Photo.13 shows the typical method to drag a gabion and to measure the drag-load where the steel wire connected to the gabion is pulled by the winch which is set on the right side in Photo. 13.

Both the static friction coefficients and dynamic ones can be summarized in Table 5 from which the findings obtained are summarized as follows.

1. The static friction coefficients used in a present design differ depending on the structure of the large-scale gabion or the foundation ground condition. The static friction coefficients for all conditions range $0.51 \sim 0.79$ and the ones of the diamond-shaped 
wire-mesh and the grid-shaped one at the crushed stone and sandy soil ground range $0.61 \sim 0.74$ and $0.77 \sim 0.79$, respectively. Furthermore, it can be found that the ones at mat-placed ground are generally smaller than that at crushed-stone and sandy soil one. This indicates that it's necessary to pay attention to use a sheet of mat at the bottom of gabions.

2. The static friction coefficients obtained in these tests are same with or more than that in the cases of gravel layers and sand layers shown in Table 4.

3. On the other hand, the dynamic ones range $0.48 \sim 0.74$. The relations of dynamic friction coefficients between mat-placed ground and crushed-stone ground or sandy soil ground are similar with that of static friction coefficients as mentioned above.

\subsubsection{Seismic potential improvement with gabion}

The centrifuge test is conducted on the effects by the Toe Reinforcement Structure with a rigid body shown in Fig. 17(a). The test conditions and measurement system are same with the former tests in Fig. 11. The toe structure set on the bottom of the container is not fixed. However the friction coefficient between the rigid body and the surface of the bottom is measured to be 0.78 in $30 \mathrm{~g}$, the rigid body isn't moved by dynamic motion with the maximum acceleration of 485 gal. Fig. 17(b) shows the displacements of the embankment model after shaking. It can be seen that the sliding plane is shallower and each displacement measured is smaller than that without reinforcement in Fig. 12. Furthermore, it can be indicated that it isn't necessary to fix the toe structure on the ground surface and it's enough to keep the high friction coefficient not to be slid. As the rigid body, the retaining wall and the large-scaled gabion etc. can be considered as the practical toe reinforcement structures.

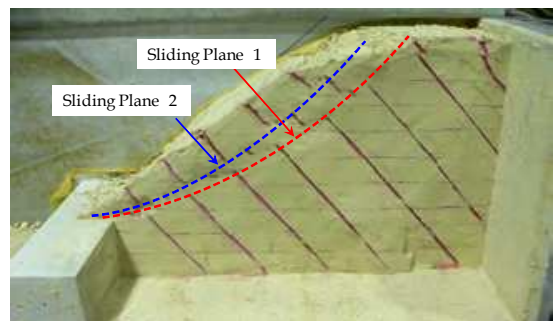

(a) Toe reinforced with rigid body

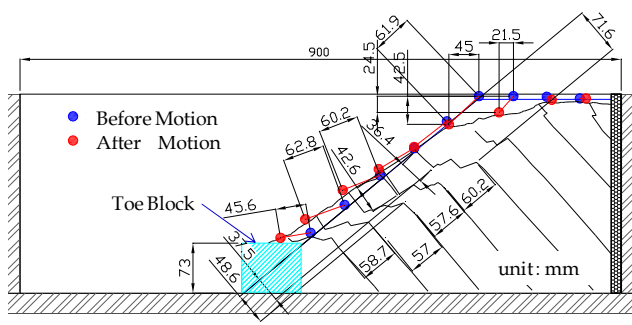

(b) Residual displacement after shaking

Fig. 17. Centrifuge test on toe reinforcement structure

\subsection{Artificial base-ground structure}

The practical examples on the application of the Artificial Base-ground Structure and the Crest Reinforcement Structure with geosynthetics are introduced as follows. Fig. 18 shows a certain site same with Fig. 16 where the road embankment indicated by Layer 4 shown in Fig. 18(a) approaching to the other construction site is constructed temporally. Fig. 18(a) shows the soil conditions in each layer, i.e. Layer 1 and Layer 2 are natural rigid base grounds, and Layer 3 is a little soft clayey deposit. The groundwater table is shown as the blue line. The soil conditions of each layer are estimated in Fig. 18(b) based on the soil investigation. 


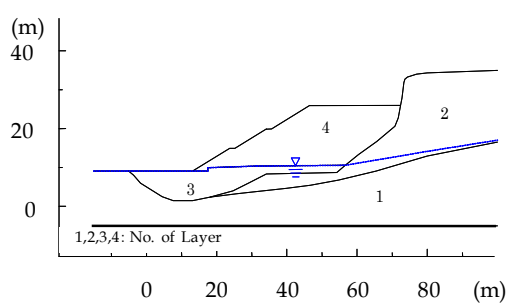

(a) Cross section

\begin{tabular}{c|c|c|c|c}
\hline $\begin{array}{c}\text { Layer } \\
\text { No. }\end{array}$ & $\begin{array}{c}\text { Saturated Unit } \\
\text { Weight }\left(\mathrm{kN} / \mathrm{m}^{3}\right)\end{array}$ & $\begin{array}{c}\text { Wet Unit Weight } \\
\left(\mathrm{kN} / \mathrm{m}^{3}\right)\end{array}$ & $\begin{array}{c}\text { Friction Angle } \\
\left({ }^{\circ}\right)\end{array}$ & $\begin{array}{c}\text { Cohesion } \\
\left(\mathrm{kN} / \mathrm{m}^{2}\right)\end{array}$ \\
\hline 1 & 18.0 & 18.0 & 0.0 & 500.0 \\
\hline 2 & 17.0 & 17.0 & 0.0 & 100.0 \\
\hline 3 & 16.0 & 16.0 & 0.0 & 28.5 \\
\hline 4 & 17.0 & 17.0 & 0.0 & 12.8 \\
\hline
\end{tabular}

(b) Conditions of soil profile

Fig. 18. Analytical model of in-situ field shown in Fig. 16

Four analytical cases of the reinforced embankment model are prepared as shown in Fig. 19. Table 6 shows the design conditions for the geosynthetics to reinforce the crest of the embankment and/or the improved strength of the embankment body as the artificial baseground where the sliding plane don't pass through.

\begin{tabular}{c|c|c|c|c}
\hline \multirow{2}{*}{ Case } & \multicolumn{2}{|c|}{ Geosynthetics } & \multicolumn{2}{c}{ Artificial Base-ground } \\
\cline { 2 - 5 } & $\begin{array}{c}\text { Number of } \\
\text { Sheet }\end{array}$ & $\begin{array}{c}\text { Tensile Strengh } \\
\left(\mathrm{kN} / \mathrm{m}^{2}\right)\end{array}$ & $\begin{array}{c}\text { Improved Area } \\
\left(\mathrm{m}^{2}\right)\end{array}$ & $\begin{array}{c}\text { Cohesion } \\
\left(\mathrm{kN} / \mathrm{m}^{2}\right)\end{array}$ \\
\hline 1 & - & - & 410 & 120 \\
\hline 2 & - & - & 385 & 169 \\
\hline 3 & 10 & 150 & 250 & 150 \\
\hline 4 & 11 & 50 & 245 & 169 \\
\hline
\end{tabular}

Table 6. Reinforcement conditions

The seismic ground motion measured at Togi City during the Noto Peninsula Earthquake in 2007 which is same with the one in Fig. 7(a) is applied with the maximum acceleration of 508 gal converted at the base ground.

The analytical results on the sliding displacement and reach length identified as shown in Fig. 19(a) are shown in Fig. 19. These results can be summarized as follows.

Case 1: However the reach length of $12.8 \mathrm{~m}$ is large, the sliding displacement of $0.16 \mathrm{~m}$ can be reduced to be small. The sliding displacement of $0.16 \mathrm{~m}$ can be judged to be Level 2 performance identified in Table 2.

Case 2: However the sliding displacement of $0.69 \mathrm{~m}$ is very large, the reach length of $1.7 \mathrm{~m}$ can be reduced to be small. Because the reach length of 1.7 is located around the shoulder of the embankmentt, Level 2 performance identified in Table 2 can be expected.

Case 3: However the reach length of $23.4 \mathrm{~m}$ is very large, the sliding displacement of $0.08 \mathrm{~m}$ can be reduced to be very small. The sliding displacement of $0.08 \mathrm{~m}$ can be judged to be Level 2 performance identified in Table 2.

Case 4: The sliding displacement of $0.23 \mathrm{~m}$ is small a little, the reach length of $2.4 \mathrm{~m}$ can be also reduced to be small a little. Both the sliding displacement and the reach length can show Level 2 performance identified in Table 2. 
The construction costs corresponding to the unit length in the longitudinal direction of the embankment among these four cases can be ordered in Case 4, Case 1, Case 2 and Case 3 from the low cost to the high one. Because the cost ratio of Case 3 against Case 4 is about 1.13, Case 4 can be indicated to be the best reinforcement plan based on the seismic performance-based design.

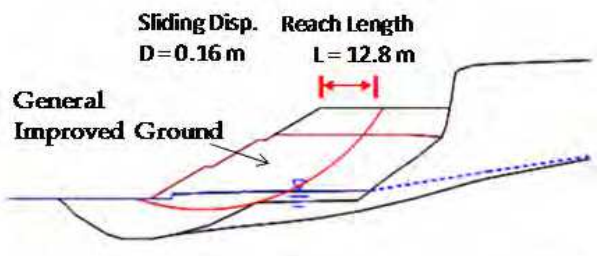

(a) Case 1: General improved ground

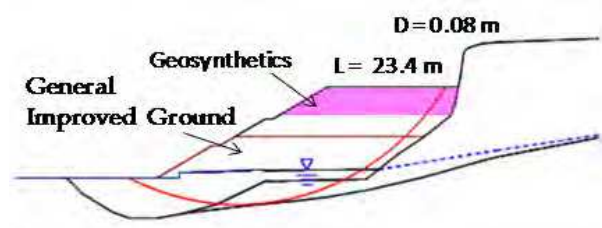

(c) Case 3: General improved ground and geosynthetics

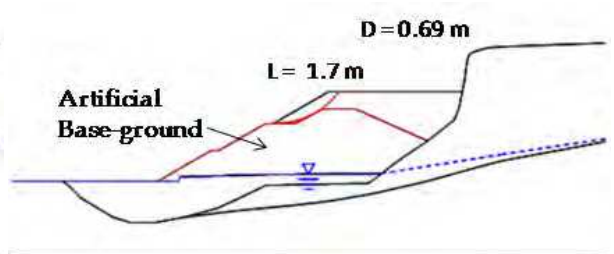

(b) Case 2: Artificial base-ground

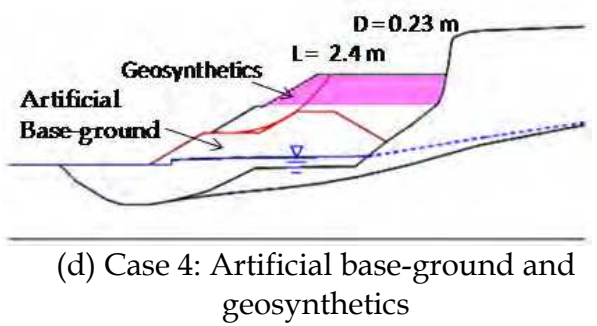

Fig. 19. Sliding characteristics according to reinforcement structures

\subsection{Barrier reinforcement structure}

The centrifuge test is conducted on the effects by Barrier Reinforcement Structure with a rigid plate shown in Photo. 14. The test conditions and measurement system are same with the former tests in Fig. 11. The under edge of the barrier structure is set to be rotated and not to be moved horizontally, i.e. assumed to be a hinge. The upper edge of the one is free and not to be connected with the side wall of the container.

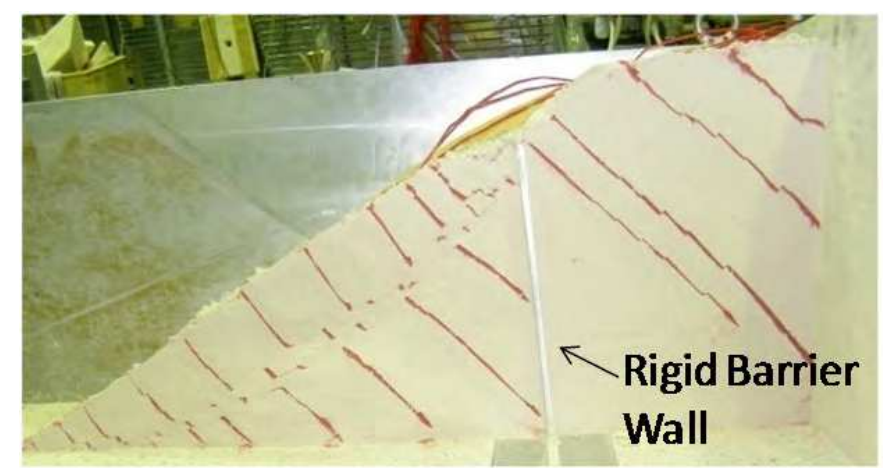

Photo 14. Centrifuge test on the Barrier Reinforcement Structure 
It can be known that however the rigid plate is inclined a little toward the slope, the sliding plane can be controlled toward the shoulder of the crest where the traffic performance isn't affected severely. If the upper edge is fixed, the effectiveness of the barrier may become larger. The Barrier Reinforcement Structure can be assumed to be effective to decrease the residual displacement at the crest of road embankments. As the rigid plate, the sheet piles and the reinforced concrete wall etc. can be considered as the practical barrier reinforcement structures.

\section{Conclusion}

Lessons obtained in this chapter can be summarized as follows.

1. Based on the damages of road embankments induced by such typical earthquakes as the 2004 Mid-Niigata Prefecture Earthquake, the 2007 Noto Peninsula Earthquake, the 2009 Suruga Bay Earthquake and the 2011 off Pacific coast of Tohoku Earthquake, several important lessons for the performance-based design of road embankments can be obtained from the engineering view points.

2. The macroscopic seismic assessment method proposed can be applied to estimate the seismic risk potential of the existing road embankments for the future detail investigation and seismic reinforcement plan.

3. The performance level proposed for the performance-based design of road embankments can be applied to set the objective performance level of the sliding failure of road embankments in the design of both new embankments and existing ones in the future.

4. The practical performance-based design concepts such as "Crest Reinforcement Structure", "Barrier Reinforcement Structure", "Artificial Reinforcement Structure" and "Toe Reinforcement Structure" can be proposed and their applications are discussed and clarified qualitatively and/or quantitatively.

\section{Acknowledgment}

The research and development on the economical seismic reinforcement technology considering the performance of the road embankments conducted in 2007 to 2009 have been supported by the Committee of New Highway Technology presided by Ministry of Land, Infrastructure and Transport. The author would like to express grateful acknowledgement to the Committee members and the cooperative researchers: Dr. Akinori Nakahira of CTI Engineering Co. Ltd., Dr. Kenji Hayashi of Forest Engineering Inc., Dr. Naoki Tatta of Maedakosen Co. Ltd., Dr. J. Jang of Shimizu Corporation and Mr. Yusuke Egawa of CTI Engineering Co. Ltd..

\section{References}

Erosion Control \& Land Slide Technical Center (2009). Design Guideline for Erosion Control Steel Structure, pp.32 (in Japanese) Japan Meteorological Agency (JMA). http://jma.go.jp/jma/press/1103/11g/kaisetsu201103112200_pdf (in Japanese)

Japan River Association (1997). Technical Code-Design II- for River \& Erosion Control Structure, pp.40 (in Japanese) 
Japan Road Association (1999). Design Criteria for Retaining Wall, p.21 (in Japanese)

National Research Institute for Earth Science and Disaster Prevention (NIED).

http://www.bosai.go.jp/kyoshin/topics/html20110311144626/main_20110311144 626.html (in Japanese)

Newmark, N. M. (1965). Effects of earthquakes on dams and embankments, Geotechnique, Vo.15, No.2, pp.139-159

Tateyama, M., Tatsuoka, F., Koseki, J. \& Horii, K. (1998). Research on Seismic Design Method of Embankment, Report of Railway research Institute, Vo.12, No.4, pp.7-12 (in Japanese)

Tatta, N., Jang, J., Tokida, K., Oda, K. \& Nakahira, A. (2009). Experimental Study on Seismic Reinforcement Method at Crest of Road Embankment by Geosynthetics, Proceedings of The International Symposium on Earthquake Geotechnical Case Histories for Performance-Based Design, Is-Tokyo, pp.963-970, Tsukuba, Japan, June 15-18

Tatta, N., Jan, J., Tokida, K., Oda, K., Nakahira, A. (2010). Seismic Reinforcement Method at Crest of Road Embankment by Geosynthetics, Proceedings of The 9th International Conference on Geosynthetics, IGC2010, pp.1611-1618, Guaruj\&aacute, Brazil, May 2327

Tokida, K., Oda, K., Nabeshima, Y. \& Egawa, Y. (2007). Damage Level of Road Infrastructure and Road Traffic Performance in The Mid Niigata Prefecture Earthquake of 2004, Structural Engineering/Earthquake Engineering, JSCE, Vol. 24, No. 1, pp.51-61.

Tokida, K., Oda, K. \& Nakahira, A. (2008). Research and Development on Economical Seismic reinforcing Technology for Road Embankment Based on Performancebased Concepts, Report of Research and Development for Improving Highway Policy, Committee of New Highway Technology of Ministry of Land, Infrastructure and Transport, No.17-4, pp.1-47 (in Japanese)

Tokida, K., Oda, K., Hayashi, K. \& Nakahira, A. (2009). Macroscopic Aseismic Assessment Method of Road Embankment, Proceedings of The International Symposium on Earthquake Geotechnical Case Histories for Performance-Based Design, Is-Tokyo, pp.1633-1638, Tsukuba, Japan, June 15-18

Tokida, K., Chen, W.Z, Nakahira, A., Echigawa, H., Minamimoto, M., Hayashi, K. (2010). Field Test on Friction Factor between Gabion and Ground, Proceedings of The 4th Japan-China Geotechnical Symposium, pp.141-147, Okinawa, Japan, April 12-14 


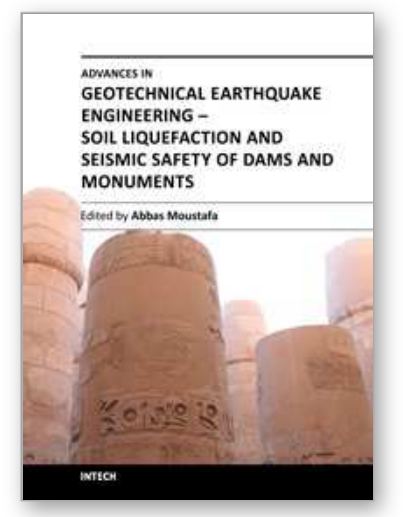

\author{
Advances in Geotechnical Earthquake Engineering - Soil \\ Liquefaction and Seismic Safety of Dams and Monuments \\ Edited by Prof. Abbas Moustafa
}

ISBN 978-953-51-0025-6

Hard cover, 424 pages

Publisher InTech

Published online 10, February, 2012

Published in print edition February, 2012

This book sheds lights on recent advances in Geotechnical Earthquake Engineering with special emphasis on soil liquefaction, soil-structure interaction, seismic safety of dams and underground monuments, mitigation strategies against landslide and fire whirlwind resulting from earthquakes and vibration of a layered rotating plant and Bryan's effect. The book contains sixteen chapters covering several interesting research topics written by researchers and experts from several countries. The research reported in this book is useful to graduate students and researchers working in the fields of structural and earthquake engineering. The book will also be of considerable help to civil engineers working on construction and repair of engineering structures, such as buildings, roads, dams and monuments.

\title{
How to reference
}

In order to correctly reference this scholarly work, feel free to copy and paste the following:

Ken-ichi Tokida (2012). Seismic Potential Improvement of Road Embankment, Advances in Geotechnical Earthquake Engineering - Soil Liquefaction and Seismic Safety of Dams and Monuments, Prof. Abbas Moustafa (Ed.), ISBN: 978-953-51-0025-6, InTech, Available from:

http://www.intechopen.com/books/advances-in-geotechnical-earthquake-engineering-soil-liquefaction-andseismic-safety-of-dams-and-monuments/seismic-potential-improvement-of-road-embankment

\section{INTECH}

open science | open minds

\author{
InTech Europe \\ University Campus STeP Ri \\ Slavka Krautzeka 83/A \\ 51000 Rijeka, Croatia \\ Phone: +385 (51) 770447 \\ Fax: +385 (51) 686166 \\ www.intechopen.com
}

\author{
InTech China \\ Unit 405, Office Block, Hotel Equatorial Shanghai \\ No.65, Yan An Road (West), Shanghai, 200040, China \\ 中国上海市延安西路65号上海国际贵都大饭店办公楼 405 单元 \\ Phone: +86-21-62489820 \\ Fax: +86-21-62489821
}


(C) 2012 The Author(s). Licensee IntechOpen. This is an open access article distributed under the terms of the Creative Commons Attribution 3.0 License, which permits unrestricted use, distribution, and reproduction in any medium, provided the original work is properly cited. 